\title{
REMOÇÃO SELETIVA DE LESÕES DE CÁRIE EM MOLARES DECÍDUOS UTILIZANDO LASER DE ER: YAG: AVALIAÇÃO CLÍNICA DAS RESTAURAÇÕES E DOS NÍVEIS \\ DE CORTISOL SALIVAR
}

\author{
Tese apresentada à Faculdade de Odontologia de \\ Ribeirão Preto da Universidade de São Paulo, para \\ obtenção do título de Doutor em Ciências. Programa: \\ Odontopediatria. \\ Área de concentração: Odontopediatria.
}

Orientadora: Silmara Aparecida Milori Corona 


\section{AUTORIZAÇÃO PARA REPRODUÇÃo}

Autorizo a reprodução e divulgação total ou parcial deste trabalho, por qualquer meio convencional ou eletrônico, para fins de estudo e pesquisa, desde que citada a fonte.

\section{FICHA CATALOGRÁFICA}

Elaborada pela Biblioteca Central do Campus USP - Ribeirão Preto

Polizeli, Silvana Aparecida Fernandes

Remoção seletiva de lesões de cárie em molares decíduos utilizando laser de Er:YAG: avaliação clínica das restaurações e dos níveis de cortisol salivar. Ribeirão Preto, 2017.

81p.: il.; $30 \mathrm{~cm}$

Tese apresentada à Faculdade de Odontologia de Ribeirão Preto da Universidade de São Paulo, para obtenção do título de Doutor em Ciências. Área de Concentração: Odontopediatria

Orientadora: Corona, Silmara Aparecida Milori

1. Cárie Dentária 2.Dente Decíduo 3.Dentes Molares 4.Crianças 5. Lasers 


\section{FolHa de APRovação}

Polizeli, SAF. Remoção seletiva de lesões de cárie em molares decíduos utilizando laser de Er:YAG: avaliação clínica das restaurações e dos níveis de cortisol salivar.

Tese apresentada à Faculdade de Odontologia de Ribeirão Preto da Universidade de São Paulo, para obtenção do título de Doutor em Ciências. Programa: Odontopediatria. Área de concentração: Odontopediatria.

Data da defesa: 1

\section{BANCA EXAMINADORA}

Prof(a). Dr(a).:

Julgamento: Assinatura:

Prof(a). Dr(a).:

Julgamento: Assinatura:

Prof(a). Dr(a).:

Julgamento: Assinatura:

Prof(a). $\operatorname{Dr}(a) .:$

Julgamento: Assinatura:

Prof(a). Dr(a).:

Julgamento: Assinatura: 



\section{Silvana Aparecida Fernandes Polizel}

Nascimento 05 de setembro de 1971

Filiação Francisco Fernandes

Aparecida Maria Fernandes

1992-1997 Graduação em Odontologia - Universidade de Mogi das Cruzes

1998-2000 Curso de aperfeiçoamento em Ortodontia Preventiva e Interceptativa SOESP (Sindicato dos Odontologistas do Estado de São Paulo)

1999-1999 Curso de aperfeiçoamento em cirurgia oral -APCD -Vila Mariana

2011-2011 Curso de aperfeiçoamento em Acupuntura para Pacientes Especiais FORP USP

2012-2012 Curso de aperfeiçoamento em Atendimento Odontológico a Pacientes Especiais. FORP - USP.

2012-2013 Especialização em Odontopediatria - AORP

2011-2013 Curso de pós-graduação (Mestrado) em odontologia. Área de concentração: Odontopediatria - FORP / USP

2013-2017 Curso de pós-graduação (Doutorado) em odontologia. Área de concentração: Odontopediatria - FORP / USP 

A DEUS primeiramente, pelo Dom da vida, Ele é que torna tudo possível, nos dando a possibilidade de enfrentarmos obstáculos jamais imaginados.

Ao meu Mestre e Amigo de todas as horas, que por meio do seu Exemplo me mostra sempre o caminho de um "Mundo Bem Melhor".

Aos meus pais Francisco e Maria, grandes exemplos de honestidade, amor, família. Meus portos seguros, sem vocês "por perto", mesmo que distantes, não seria possível tudo isso. Se eu pudesse escolhê-los-ia como pais, por todas as vidas que eu pudesse ter....Amo vocês!

Ao meu marido Sandro, por me entender nos momentos de ausência e por ser esse companheiro de vida, tão maravilhoso.

Ao meu filho Lucca, luz dos meus dias, obrigada por tentar entender a vida corrida dos adultos e me ajudar com boas e sábias palavras. Amo-o muito.

Ao meu filho Matheus, sobrinho querido que se permitiu ser filho, muito do que eu faço é pra você! Amo-te.

Ao meu querido irmão Leonardo, sempre com palavras alegres de conforto nos momentos dificeis.

As minhas sobrinhas Isadora e Esther, minhas pequenas joias.

A todos os meus familiares pelo exemplo de amor e união, onde todas as dificuldades são vencidas e as alegrias compartilhadas. 
A minha orientadora Profa. Dra. Silmara Aparecida Milori Corona, a melhor orientadora que eu podia ter. Conviver com você foi e é sempre muito bom. Ser humano de coração enorme e de uma compreensão sem limites. Sil, você é e sempre será muito especial para mim.

Ao meus amigos, Rodrigo Alexandre Valério e Mariana Alencar Nemezio por entenderem minha correria, pelas risadas, pelo exemplo de grandes pessoas que você são, companheiros de pós graduação, sempre dispostos a ajudar, sem vocês eu não teria chegado onde estou.

Á doutoranda Fabiana Curylofo pela participação em varias etapas deste estudo. .Fabi, obrigada pelo carinho, eficiência e dedicação com que você nos ajudou a realizar esse trabalho.

Aos docentes do departamento de Clínica Infantil e do departamento de Odontologia Restauradora da Faculdade de Odontologia de Ribeirão Preto, São Paulo, pelos ensinamentos, amizade e atenção. Tenho muita admiração por todos vocês!

À amiga Rosemary Alves De Sá, pela formatação desta tese de doutorado e por estar sempre disposta a me ajudar.

À amiga Micheli Cristina Leite Rovanholo, por toda a ajuda e paciência partilhadas durante a pós graduação. Você é uma pessoa, que guardarei no meu coração para sempre.

Às amigas de pós graduação pela amizade durante o doutorado, cada uma de vocês deixa lembranças muito boas na minha vida.

As crianças que participaram deste trabalho e seus responsáveis que sempre se apresentaram disponiveis para nos ajudar, cumprindo com grande empenho todas as orientações passadas e sem os quais a execução deste estudo não seria possível. 
À Faculdade de Odontologia de Ribeirão Preto, da Universidade de São Paulo, em nome de sua diretora Profa. Dra. Léa Assed Bezerra da Silva.

A Comissão de Pós-Graduação da Faculdade de Odontologia de Ribeirão Preto da Universidade de São Paulo na pessoa do Presidente Prof. Dr. Manoel Damião de Sousa Neto e da Suplente Profa. Dra. Raquel Assed Bezerra Segato.

Ao Programa de Pós-Graduação em Odontopediatria da Faculdade de Odontologia de Ribeirão Preto da Universidade de São Paulo em nome de sua Presidente Profa. Dra. Raquel Assed Bezerra Segato e da Suplente Profa. Dra. Léa Assed Bezerra da Silva.

Aos funcionários do Departamento de Clínica Infantil da Faculdade de Odontologia de Ribeirão Preto, Universidade de São Paulo pela amizade, paciência, disponibilidade, e ajuda. Vocês também foram grandes mestres durante esta etapa.

As funcionárias da seção de Pós-Graduação da Faculdade de Odontologia de Ribeirão Preto da Universidade de São Paulo, obrigada pela amizade, atenção e paciência em todos os momentos.

Aos funcionários dos Departamentos de Odontologia Restauradora e Cirurgia e Traumatologia Buco-Maxilo-Facial e Periodontia da Faculdade de Odontologia de Ribeirão Preto - Universidade de São Paulo, pela atenção e colaboração durante o doutorado.

Ao amigo e pedagogo Silvio de Almeida Filho pela leitura e pelas sugestões de revisão ortográfica e gramatical dessa tese. 
A FAPESP (Proc. 2014/ 07942-4), pela concessão de Auxîlio Pesquisa, o que permitiu a execução deste trabalho.

Ao CNPq (Proc. 307520/2013-7) pela concessão de Bolsa de Produtividade em Pesquisa.

A CAPES pela bolsa de Doutorado concedida. 
"A menos que modifiquemos a nossa maneira de pensar, não seremos capazes de resolver os problemas causados pela forma como nos acostumamos a ver o mundo"

Albert Einstein 

Polizeli, SAF. Remoção seletiva de lesões de cárie em molares decíduos utilizando laser de Er:YAG: avaliação clínica das restaurações e dos níveis de cortisol salivar. Ribeirão Preto, 2017. 81p. [Tese de Doutorado]. Ribeirão Preto: Faculdade de Odontologia da Universidade de São Paulo; 2017.

\section{RESUMO}

A odontologia minimamente invasiva sugere que durante a realização de preparos cavitários se remova menor quantidade de substrato dentário sadio associado ao uso de materiais adesivos, com o intuito de oferecer durante o tratamento odontológico menor ansiedade e maior conforto ao paciente. Esse estudo teve por objetivo avaliar os níveis de cortisol salivar da criança durante a remoção seletiva de lesões de cárie utilizando laser de Er:YAG e posterior análise longitudinal das restaurações realizadas. Foram selecionadas crianças entre 7 a 10 anos, que apresentassem duas lesões de cárie ativas em dentina localizadas nas superfícies oclusal e proximal (classe II) de molares decíduos. Os dentes de cada criança foram distribuídos em dois grupos aleatoriamente: 1) Laser de Er:YAG (250mJ/4 Hz) e 2) Método convencional (baixa rotação). A dosagem do hormônio cortisol foi realizada por meio de análise imunoenzimática da saliva em 2 momentos: 7 dias antes dos procedimentos e durante a remoção das lesões de cárie. Foi realizada proteção pulpar indireta utilizando cimento de hidróxido de cálcio e cimento de ionômero de vidro nas cavidades profundas e apenas cimento de ionômero de vidro nas cavidades médias. As cavidades foram preparadas e em seguida restauradas empregando o sistema restaurador Adper Single Bond 2/ Filtek Supreme (3M). Para análise clínica das restaurações, três profissionais calibrados e experientes utilizaram os critérios US Public Health Service modificados e exame fotográfico. Para a análise da réplica da restauração os dentes foram moldados e vazados com resina epóxi. A adaptação marginal foi analisada por MEV. As análises clínica e da réplica foram realizadas nos períodos de 7 dias, 6 e 12 meses após a confecção da restauração. Os dados foram analisados por ANOVA e teste de Tukey ( $\alpha=5 \%)$. Os níveis de cortisol foram maiores durante a remoção seletiva de cárie, independentemente do método utilizado ( $p>0,05$ ). Após 12 meses, não houve evidência de diferença na retenção, adaptação marginal, descoloração, contorno axial e cárie secundária das restaurações realizadas em cavidades preparadas por ambos os métodos. A análise por MEV revelou que os dentes irradiados com laser apresentaram $10 \%$ de fendas na extensão total da restauração. Para os dentes preparados pelo metodo convencional, $20 \%$ das fendas foram encontradas na margem cavosuperfícial. A utilização do laser de Er:YAG não aumentou os níveis de cortisol salivar quando comparado ao metodo convencional e não influenciou o desempenho clínico de restaurações de classe II, sendo um método alternativo para a remoção de lesões cárie em crianças.

Palavras-Chave: Cárie Dentária. Crianças. Dente Decíduo. Dentes Molares. Lasers. 

Polizeli, SAF. Selective caries removal in primary molars using Er:YAG laser: clinical evaluation of restorations and salivary cortisol levels. Ribeirão Preto, 2017. 81p. [Doctoral thesis]. Ribeirão Preto: Faculty of Dentistry, University of São Paulo; 2017.

\begin{abstract}
Minimally invasive dentistry suggests that during the preparation of cavity preparations, lesser amount of healthy dental substrate associated with the use of adhesive materials is removed, with the purpose of offering less anxiety and greater patient comfort during dental treatment. This study aimed to evaluate the salivary cortisol levels of the child during the selective removal of cáries lesions using Er:YAG laser and later longitudinal analysis of the restorations performed. Children between 7 and 10 years of age were selected to present two lesions of active cáries in dentin located on the occlusal and proximal surfaces (class II) of decíduous molars. The teeth of each child were distributed in two groups randomly: 1) Er:YAG laser (250mJ / $4 \mathrm{~Hz}$ ) and 2) Conventional method (low rotation). The dosage of the hormone cortisol was performed by means of immunoenzymatic analysis of the saliva in 2 moments: 7 days before the procedures and during the removal of the cáries lesions. Indirect pulp protection was performed using calcium hydroxide cement and glass ionomer cement in the deep wells and only glass ionomer cement in the medium wells. The wells were prepared and then restored using the Adper Single Bond 2 / Filtek Supreme (3M) restorative system. For clínical analysis of the restorations, three calibrated and experienced professionals used the modified US Public Health Service criteria and photographic examination. For the analysis of the réplica of the restoration the teeth were cast and cast with epoxy resin. The marginal adaptation was analyzed by SEM. Clínical and réplicate analyzes were performed in the 7 day, 6 and 12 month periods after the restoration. Data were analyzed by ANOVA and Tukey's test $(\alpha=5 \%)$. Cortisol levels were higher during the selective removal of cáries, regardless of the method used ( $p>0.05$ ). After 12 months, there was no evidence of difference in retention, marginal adaptation, discoloration, axial contour and secondary cáries of restorations performed in wells prepared by both methods. SEM analysis revealed that the laser irradiated teeth presented $10 \%$ of the total length of the restoration. For teeth prepared by the conventional method, $20 \%$ of the slits were found in the cavosuperficial margin. The use of the Er:YAG laser did not increase the levels of salivary cortisol when compared to the conventional method and did not influence the clínical performance of class II restorations, being an alternative method for the removal of cáries lesions in children.
\end{abstract}

Keywords: Children. Decíduos Tooth. Dental Cáries. Primary Molars. Lasers 



\section{LISTA DE ILUSTRAÇõES}

Figura 1- Desenho experimental do estudo

Figura 2- CONSORT= esquema explicativo do recrutamento, atribuição, acompanhamento e análise de dados final

Figura 3- Remoção da cárie utilizando método convencional (A) ou laser Er:YAG (B). A1: lesão de cárie ativa nas superfícies oclusal e proximal de molar decíduo, A2: aspecto inicial da restauração (baseline), A3: restauração após 6 meses, A4: restauração após 12 meses. B1: lesão de cárie ativa nas superfícies oclusal e proximal de molar decíduo; B2: aspecto inicial da restauração ( baseline), B3: restauração após 6 meses; B4: a restauração após 12 meses.

Figura 4- Microscopia eletrônica de varredura das restaurações realizadas em cavidades preparadas pelo método convencional (A) ou laser Er:YAG (B). A1: restauração inicial; A2: restauração após 6 meses; A3: restauração após 12 meses. B1: restauração inicial; B2: restauração após 6 meses; B3: restauração após 12 meses. A seta indica a interface adesiva 



\section{LISTA DE TABELAS}

Tabela 1: Critérios USPHS modificados que foram utilizados durante a avaliação das restaurações..

Tabela 2: Níveis de cortisol salivar ( $\mathrm{nmol} / \mathrm{L}$ ) obtidos durante a remoção seletiva da lesão de cárie, em cavidades de classe II de molares decíduos $(n=24)$

Tabela 3: Resultados da análise clínica das restaurações de classe II utilizando-se o critério USPHS modificado. 



\section{Lista de AbreViaturas e Siglas}

EMLA: Eutectic Mixture of Lidocaine and Prilocaine (Mistura eutética de lidocaína e prilocaína)

Er:YAG: Érbio Itrio-Alumínio-Granada

Hz: $\quad$ Hertz

ISO: International Organization for Standardization

J/cm2: Joule por centímetro quadrado

JPEG: Joint Photographics Experts Group

KV: $\quad$ Volt

mA: $\quad$ Miliampére

MEV: microscopia eletrônica de varredura

mg: Miligrama

min: $\quad$ Minuto

mJ: $\quad$ Milijoule

$\mathrm{mL} \quad \quad$ Mililitro

mm: Milímetro

MSP: $\quad$ Modo super pulso

$\mathrm{mw} / \mathrm{cm}^{2}$ : Mili-watts por centímetro quadrado

nm: Nanômetro

no: $\quad$ Número

RPM: Rotações por minuto

USPHS: $\quad$ United States Public Health Service 



\section{LISTA DE Símbolos}

$\mu \mathrm{m}$ : Micrometros

\%: Porcentagem

$\mu \mathrm{L}$ : Microlitro 

1. INTRODUÇÃO

2. PROPOSIÇÃO

3. MATERIAL E MÉTODO

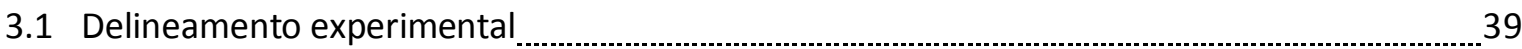

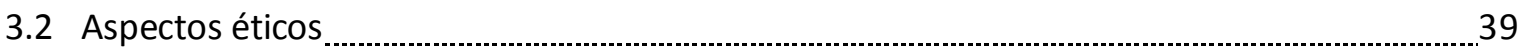

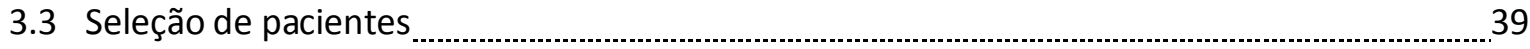

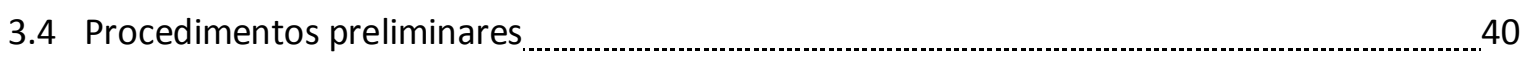

3.5 Medidas de biossegurança

3.6 Remoção seletiva das lesões de cárie .............................................................................................. 41

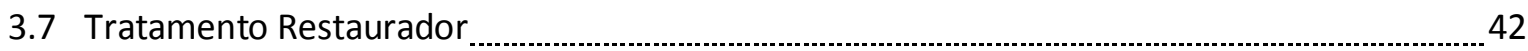

3.8 Avaliação do estresse por meio da dosagem de cortisol salivar _............................................. 43

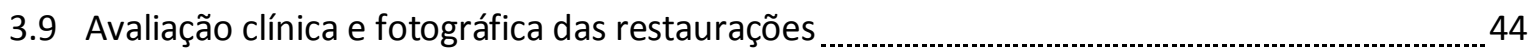

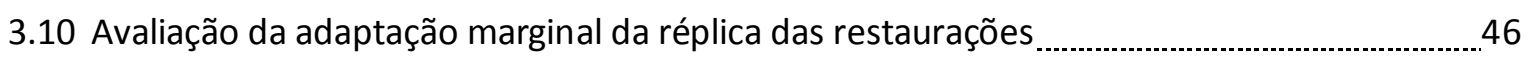

3.11 Análise estatística

4. RESULTADOS

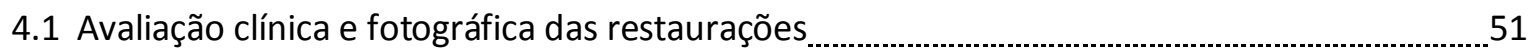

4.2 Avaliação da adaptação marginal da réplica das restaurações ……………………....................... 54

5. DISCUSSÃO

6. CONCLUSÃO

REFERÊNCIAS

ANEXOS 

1. Introduç̃o e Justificativa 



\section{INTRODUÇãO E JUSTIFICATIVA}

A odontologia minimamente invasiva preconiza a máxima preservação do tecido dentário sadio em todos os procedimentos odontológicos (Tyas et al., 2000, Ricketts et al., 2013; Shwendicke et al., 2013). Quando os métodos preventivos não são aplicados de forma adequada, ocorre a instalação das lesões de cárie e o preparo da cavidade torna-se necessário, e dessa forma, a remoção de tecido dentário deve ser a mais limitada possível, pois os materiais restauradores existentes não apresentam condições de suprir completamente as características funcionais do esmalte, da dentina e do cemento quando esses substratos se apresentam sadios na cavidade bucal. Esse conceito de mínima intervenção e máxima preservação dos tecidos dentários torna importante e indispensável a distinção clínica entre a dentina infectada (necrosada) e a dentina afetada (remineralizável), uma vez que essas características apresentam fundamental importância e tem caráter decisivo entre o que deve ser removido e o que convém ser preservado durante a remoção de tecido cariado (Massara et al., 2002; Léda et al., 2015).

A dentina infectada refere-se à camada mais externa do tecido cariado, e se apresenta como um tecido infectado, necrótico e irreversivelmente desorganizado, enquanto que, a dentina afetada está localizada mais internamente, apresentando-se menos desorganizada e potencialmente remineralizável (Fusayama, 1979). O sucesso desta técnica baseia-se na seletividade da remoção do tecido cariado (Kidd, 2004), reduzindo a quantidade de bactérias no interior da cavidade sem, contudo remover o tecido passível de remineralização (Kidd, 2004; Maltz et al., 2007; Thompson et al., 2008; Maltz et al., 2012).

A técnica de remoção seletiva de tecido cariado se torna interessante e preferível, quando comparada à técnica de remoção total do tecido cariado, uma vez que, os tecidos dentários sadios são preservados, resultando num menor risco de exposição pulpar (Ricketts et al., 2006; Thompson et al., 2008), estimulando o processo de esclerose tubular e deposição de dentina terciária, reduzindo assim a permeabilidade da dentina remanescente (Kidd, 2004). Em dentes decíduos essa técnica tem sido considerada vantajosa, diminuindo o número de microorganismos cariogênicos na dentina (O`Connell, 2012; Ribeiro et al., 2012).

A procura constante por procedimentos que proporcionem ao paciente um tratamento menos traumático e mais conservador durante os procedimentos odontológicos, tem estimulado e originado o desenvolvimento de tecnologias para a remoção de lesões de 
cárie, que sejam alternativas aos instrumentos rotatórios convencionais em alta e baixa rotação, como o laser de Er:YAG, do qual o comprimento de onda de 2,94 $\mu \mathrm{m}$, coincide com o pico máximo de absorção da água e dos radicais hidroxila presentes na hidroxiapatita (Paghdiwala, 1991; Keller; Hibst, 1997). O laser de Er:YAG promove desnaturação parcial da matriz do esmalte, formação de um bloco mineral que retarda a difusão dos ácidos e, consequentemente, reduz a desmineralização (Ying et al., 2004).

O laser de Er:YAG atua promovendo a ablação eficaz do tecido cariado (Aoki et al., 1998), e remove-o por meio de micro explosões, podendo ser utilizado para remoção de lesões de cárie em dentes permanentes (Aoki et al., 1998; Dommisch et al., 2008; Krause et al., 2008; Hamidi, 2015) e decíduos (Keller, Hibst, 1997; Evans et al., 2000; Kato et al., 2003; Liu et al., 2006; Jacobson; Asgari, 2008; Kornblit et al., 2008; Tanboga et al., 2011; Valério et al., 2015; Polizeli et al., 2016), eliminando o desconforto promovido pela vibração, ruídos e pressão resultantes do uso de aparelhos rotatórios convencionais durante a remoção das lesões de cárie (Keller; Hibst, 1997; Cozean et al., 1997; Evans et al., 1998; Bohari et al., 2012), especialmente no atendimento odontológico de crianças, as quais relacionam esse medo com experiências subjetivas de dor e trauma e não com a patologia dental propriamente dita (Townend et al., 2000; Montedori et al., 2016; Soares et al., 2016). O tratamento com laser Er:YAG não afeta os pesos percentuais médios de $\mathrm{Ca}, \mathrm{K}, \mathrm{Mg}, \mathrm{Na}$, e $\mathrm{P}$ presentes nos dentes decíduos, sendo considerado seguro para preparação da cavidade nesses dentes (Guler et al., 2014), bem como as restaurações realizadas em cavidades tratadas com Laser de Er:YAG demonstraram uma performance clínica aceitável de acordo com os critérios USPHS (Valério et al., 2015)

A aquisição e constância de atitudes negativas diante do tratamento odontológico é um processo que muitas vezes tem início na infância (Abreu et al., 2011), e pode persistir na adolescência, levando o indivíduo a apresentar um comportamento inadequado até a idade adulta, evitando o tratamento odontológico (Chapman; Kirby-Tumer, 1999).

A ansiedade é uma apreensão generalizada relacionada ao desconhecido ou a uma situação nova, ao passo que o medo é um estado de apreensão com base nas experiências reais, na memória e imaginação (Singh et al., 2009).

O cortisol, também chamado de "hormônio do estresse", é secretado pelo córtex da glândula adrenal. Ele regula o metabolismo de carboidratos, proteínas, gorduras e água, mantém as reações vasculares, regula a sensibilidade do sistema nervoso, regula o número 
de células sanguíneas e afeta a resposta humana ao estresse (Ganong, 1991). A medição do cortisol salivar tem sido amplamente utilizada em pesquisas pediátricas há mais de vinte anos como biomarcador da atividade do eixo hipotalâmico da glândula adrenal pituitária (HPA) durante a atividade normal e em resposta ao estresse (Keil, 2012), tem sido utilizado como indicador em estudos de avaliação do estresse e medo em tratamentos odontológicos (Akyuset al., 1996; Kandemir et al., 1997; Kambalimath, 2010; Furlan, et al., 2012; Yfanti et al., 2014; Patil et al., 2015; Queiroz et al., 2015). O cortisol salivar é indicador de cortisol livre ou cortisol biologicamente ativo no soro humano e a avaliação dos níveis de cortisol salivar caracteriza-se por ser uma técnica não-invasiva , fácil (Hanrahan et al., 2006; Shah et al., 2009; Jafarzadeh, 2013; Patil et al., 2015; van Ockenburg et al., 2015) e confiável em lactentes e crianças, promovendo resultados mais precisos e obtenção de amostras sem aumentar as preocupações éticas (Keil, 2012).

O estresse e o pânico durante o tratamento odontológico restaurador, especialmente em pacientes infantis, podem ser reduzidos consideravelmente utilizando-se o laser de Er:YAG na remoção de lesões de cárie, propiciando procedimentos mais confortáveis para o paciente (Keller et al., 1998). A utilização dessa tecnologia tende a eliminar o desconforto produzido pelo ruído e vibração dos instrumentos rotatórios convencionais e muitas vezes torna menor a necessidade do uso de anestesia local infiltrativa (Keller; Hibst, 1997; Pelagalli et al., 1997; Kato et al., 2003; Takamori et al., 2003; Krause et al., 2008). A utilização do laser de Er:YAG tem sido bem aceita pelos pacientes para a remoção de tecido cariado (Cozean et al., 1997; Keller; Hibst, 1997), apesar de resultar num maior tempo de trabalho (Aoki et al., 1998; Valério et al., 2015).

A utilização dessa tecnologia para remoção de tecido dentário cariado (Cozean et al., 1997; Keller; Hibst, 1997; Aoki et al., 1998; Evans et al., 2000; Kato et al., 2003; Liu et al., 2006; Dommisch et al., 2008; Jacobson; Asgari, 2008; Kornblit et al., 2008; Krause et al., 2008; Tanboga et al., 2011;) tem levado a um aumento no número de pesquisas com a utilização do laser de Er:YAG (Armengol et al., 2000; Corona et al., 2001; Benjamin, 2002; Bohari et al., 2012; Zhang et al., 2013; Valério et al., 2015; Correa et. al, 2016; Polizeli et al., 2016; Galafassi et. al, 2017), proporcionando ao paciente menor desconforto e diminuição da dor durante o ato operatório (Liu et al., 2006; Mosskull, Bagesund, 2012). 
Devido à escassez de ensaios clínicos randomizados avaliando o estresse apresentado por crianças durante a remoção seletiva de lesões de cárie em dentes decíduos utilizando o laser de Er:YAG, bem como análise longitudinal das restaurações realizadas, o objetivo desse estudo foi avaliar os níveis de cortisol salivar das crianças durante a remoção seletiva de cárie, o desempenho clinico das restaurações e a adaptação marginal da réplica da restaurações. As hipóteses nulas testadas foram que os níveis de cortisol salivar são semelhantes durante a remoção seletiva da lesão de cárie, utilizando o método convencional ou o laser de Er:YAG e que o método de remoção seletiva da lesão de cárie não influencia no comportamento longitudinal das restaurações de resina composta classe II em dentes decíduos. 
2. Proposição 



\section{PROPOSIÇÃo}

O presente estudo teve por objetivo avaliar os níveis de cortisol salivar da criança durante a remoção seletiva de lesões de cárie utilizando laser de Er:YAG e realizar análise clínica das restaurações realizadas. Para tal, o estudo teve os seguintes objetivos específicos:

- Avaliar os níveis de cortisol salivar da criança durante a remoção seletiva das lesões de cárie em molares decíduos utilizando o laser de Er:YAG, por meio da análise imunoenzimática.

- Avaliar clinicamente as restaurações de resina composta após remoção seletiva de lesões de cárie utilizando laser de Er:YAG nos períodos após 7 dias, 6 meses e 1 ano, por meio de exame clínico utilizando os critérios US Public Health Service (USPHS) modificados e análise fotográfica.

- Avaliar a adaptação marginal da réplica da restauração em microscopia eletrônica de varredura, por meio do cálculo da porcentagem da integridade marginal. 

3. Material e Método 



\section{Material e Método}

\subsection{Delineamento experimental}

Para realização do experimento foram selecionadas crianças que apresentaram pelo menos 2 lesões de cárie ativas, com cavitação atingindo dentina, localizadas nas superfícies oclusal e proximal de molares decíduos, de acordo com delineamento em blocos completos e casualizados.

O fator em estudo foi o método empregado para a remoção seletiva de lesões de cárie, em dois níveis: 1) Laser de Er:YAG $(250 \mathrm{~mJ} / 4 \mathrm{~Hz})$ e 2) Método convencional (Contra ângulo 1:1 L micro series e motor elétrico, com sistema de indução eletromagnética, apresentando 40.000 RPM e torque de $2.5 \mathrm{~N} . \mathrm{cm}$ ).

As variáveis de resposta foram: 1) avaliação quantitativa do estresse durante a remoção seletiva das lesões de cárie, por meio de teste imunoenzimático para dosagem de cortisol salivar (mol/L); 2) avaliação clínica e fotográfica qualitativa das restaurações de resina composta realizadas nas cavidades preparadas nos períodos após 7 dias da realização restauração, 6 meses e 1 ano, por meio de exame clínico USPHS modificado; 3) avaliação quantitativa da adaptação marginal da réplica da restauração em microscopia eletrônica de varredura, por meio do cálculo da porcentagem da integridade marginal, também realizada nos períodos após 7 dias da realização da restauração, 6 meses e 1 ano.

\subsection{Aspectos éticos}

O projeto foi aceito no Comitê de Ética em Pesquisa da Faculdade de Odontologia de Ribeirão Preto - USP (número CAAE 21018413000005419). Os pais ou responsáveis pelas crianças foram esclarecidos quanto à metodologia do estudo e também foram informados sobre seus direitos de desistir da pesquisa em qualquer fase da execução da mesma. Recebidas as informações, o termo de consentimento livre e esclarecido e o termo de assentimento de menor foram assinados, de acordo com as normas do Comitê de Ética desta mesma instituição.

\subsection{Seleção de pacientes}

O cálculo do tamanho da amostra foi baseado na quantidade de crianças examinadas ao longo de um período de 12 meses na Clínica de Odontopediatria da Faculdade de 
Odontologia de Ribeirão Preto, Universidade de São Paulo. O nível de confiança foi estimado em $95 \%$ com um erro de 5\%, resultando em 16 crianças participantes. Assim, estabeleceu-se $n=20$.

Foram examinadas 1.115 crianças, com idades entre 7 e 10 anos, de ambos os gêneros. As crianças foram avaliadas clinicamente e radiograficamente utilizando o sensor de radiografia digital (CDR Elite, Fona, São Paulo, SP) com posicionador. Os critérios de inclusão das crianças foram: duas lesões de cárie ativas em dentina, localizadas sobre a superfície oclusal e proximal (classe II) de molares decíduos (cavidades profundas e médias), com vitalidade pulpar e no máximo metade da raiz reabsorvida, com ausência de selantes e restaurações de amálgama, cimento de ionômero de vidro e de resina composta.

Os molares decíduos foram classificados de acordo com a sua fase de reabsorção em: inicial, um quarto da raiz reabsorvida, metade da raiz reabsorvida e reabsorção completa. Os dentes incluídos apresentavam resposta positiva ao teste térmico realizado com Endofrost (Roeko, Langenau, Alemanha).

Foram excluídas da pesquisa as crianças que apresentaram dentes com dor e/ou sensibilidade espontânea, fístula, edema, mobilidade não compatível com o estágio de rizólise e, ao exame radiográfico, presença de radiolucidez na região de furca e periápice, aumento do espaço periodontal e reabsorção dentária interna/externa.

Foram selecionadas 71 crianças para este estudo. Destas, 47 se recusaram a participar. Assim foi realizada a análise dos níveis de cortisol salivar em 24 crianças, durante a remoção das lesões de cárie. Quatro crianças não regressaram para o polimento da restauração, assim, 20 crianças $(n=20)$ foram incluídas na avaliação clínica das restaurações. A figura 2 representa o diagrama CONSORT, que discrimina detalhadamente a forma de recrutamento, alocação, monitoramento e análise dos participantes.

\subsection{Procedimentos preliminares}

As crianças receberam profilaxia dentária e instrução individual de higiene bucal. Os dentes que necessitaram de tratamento, e não foram selecionados para o estudo, foram posteriormente tratados. A calibração do operador e dos avaliadores foi feita através da avaliação das restaurações dentárias realizadas em manequins (teste Kappa =0,92). 


\subsection{Medidas de biossegurança}

A sequência técnica deste trabalho foi realizada no Laboratório de Pesquisa em Laser, do Departamento de Odontologia Restauradora da Faculdade de Odontologia de Ribeirão Preto da Universidade de São Paulo obedecendo às normas de segurança: sala dotada de luz externa de aviso, que permaneceu acesa durante a utilização do equipamento, porta com trava, exaustor e sistema de controle de temperatura (mantida em torno de $23^{\circ} \mathrm{C}$ ). Todos os indivíduos presentes durante os procedimentos com laser utilizaram óculos de proteção para o comprimento de onda específico do aparelho.

\subsection{Remoção seletiva das lesões de cárie}

A randomização dos pacientes foi realizada usando uma planilha de computador. Com o auxílio de um gerador de números aleatórios disponível no endereço eletrônico: http://randomnumbergenerator.intemodino.com/pt/, as crianças selecionadas tiveram seus nomes numerados para a escolha do tratamento. Os dentes foram distribuídos aleatoriamente pelos grupos: 1) laser de Er:YAG ou 2) Método convencional. Os tratamentos foram realizados em sessões separadas, com intervalo de 7 dias entre as sessões.

O anestésico EMLA (Laboratório Astrazeneca, Cotia SP, Brasil), foi cuidadosamente aplicado por meio de haste flexível com ponta de algodão (Cotonete ${ }^{\circledR}$, Johnson \& Johnson, São José dos Campos, SP) na mucosa jugal e nas papilas gengivais dos dentes decíduos e foi realizada a injeção da solução anestésica local contendo mepivacaína $2 \%$ associada à epinefrina 1:100.000. A mepivacaína foi o anestésico de escolha por possuir ação potente, mesmo em pequenas concentrações, e incidência de resposta alérgica praticamente inexistente (Ram \& Peretz, 2002). Além disso, o fato da analgesia promovida por este anestésico não ocorrer por intervalo de tempo muito prolongado, torna-se particularmente interessante nos casos em que os procedimentos não são tão longos, e também para crianças que tem o hábito de morder os lábios (Moore \& Hersh, 2010).

Antes da colocação do grampo para o isolamento absoluto do campo operatório, foi realizada a seleção da cor da resina composta (Z350; 3M ESPE, São Paulo, SP, Brasil) que foi utilizada nas restaurações das cavidades, por meio de escala de cores Vita 3D (Wilcos do Brasil Indústria e Comércio Ltda, Petrópolis, RJ, Brasil).

Os dentes receberam isolamento absoluto com lençol de borracha (Madeitex, São José dos Campos, SP, Brasil), e foram utilizados grampos de vários números (Duflex, 
SSWhite, Rio de Janeiro, RJ, Brasil), de acordo com a morfologia dentária de cada molar decíduo (Croll, 1995). Após a conclusão do isolamento absoluto, foi realizada a remoção seletiva da lesão de cárie, empregando laser de Er:YAG no molar decíduo de um hemiarco ou método convencional no molar decíduo contralateral, de acordo com sorteio previamente realizado.

A remoção seletiva do tecido cariado foi realizada na camada superficial de dentina necrótica das paredes circundantes, utilizando laser de Er:YAG ou método convencional. $\mathrm{O}$ tecido cariado foi completamente removido das paredes circundantes, e na parede pulpar, foi mantida a dentina afetada, endurecida e resistente à curetagem, passível de remineralização (Kidd, 2004; Thompson et al., 2008; Maltz et al., 2012). A verificação da remoção seletiva da lesão de cárie foi realizada de acordo com critérios clínicos de dureza, empregando curetas (Maltz et al., 2007).

No grupo experimental, a remoção seletiva da lesão de cárie foi realizada com laser de Er:YAG (Fidelis Er III, Fotona, Ljubljana, Eslovênia), utilizando caneta (R02), no modo nãocontato, distância focal de $7 \mathrm{~mm}$, energia pulsátil de $250 \mathrm{~mJ}$, frequência de pulsos de $4 \mathrm{~Hz}$ (Krause et al., 2008), diâmetro de saída do feixe de 0,9 mm, densidade de energia de 39 $\mathrm{J} / \mathrm{cm}^{2}$, com fluxo de água de $6 \mathrm{~mL} / \mathrm{min}$ determinados (Valério et al., 2015; Polizeli et al., 2016).

No grupo controle, a remoção seletiva do tecido cariado foi realizada com brocas carbide esféricas (KG Sorensen, Barueri, SP, Brasil) compatíveis com o tamanho da cavidade, em baixa rotação (Contra ângulo 1:1 L micro series, Gnatus, Ribeirão Preto, SP, Brasil). Quando necessário, o acesso à lesão de cárie (remoção do esmalte superficial) foi realizado com pontas diamantadas esféricas, também compatíveis com a cavidade (KG Sorensen, Barueri, SP, Brasil), em alta rotação (Contra ângulo 1:5 L micro series, Gnatus, Ribeirão Preto, SP, Brasil).

\subsection{Tratamento Restaurador}

Após a remoção seletiva das lesões de cárie, foi realizada proteção pulpar indireta de acordo com a profundidade da lesão de cárie. Nas cavidades profundas foi utilizado o cimento de hidróxido de cálcio (Dycal; Dentisply Indústria e Comércio Ltda, Petrópolis, RJ, Brasil), seguida da aplicação do cimento de ionômero de vidro (Ketac Molar; 3M, São Paulo, 
Brasil). Nas cavidades médias, foi utilizado apenas o cimento de ionômero de vidro (Ketac Molar; 3M, São Paulo, Brasil).

A cavidade foi condicionada com gel de ácido fosfórico 37\% por 15 segundos em esmalte e 7 segundos em dentina (Van Meerbeek et al., 1994, Pimenta et al., 2010), lavagem da cavidade com água durante 1 minuto, remoção do excesso de água com cânula de sucção e posterior secagem da cavidade com bolinhas de algodão.

O sistema adesivo Adper Single Bond 2 (3M ESPE, São Paulo, SP, Brasil) foi aplicado em duas camadas com aplicador descartável (KGBrush, KG Sorensen, Cotia, SP, Brasil), intercaladas por um jato de ar por 5 segundos, e fotoativado (Gnatus, Ribeirão Preto, SP, Brasil), seguindo instruções do fabricante.

Com auxílio do porta-matriz tipo Tofflemire (Golgran, São Caetano do Sul, SP, Brasil) e matriz de aço inoxidável estabilizada com cunha de madeira (Cenci et al., 2006) a restauração foi realizada aplicando-se resina composta Z350 (3M ESPE, São Paulo SP, Brasil) em pequenos incrementos com espátula para resina, fotoativado por 20 segundos cada, devolvendo a forma anatômica aos dentes.

Terminada a restauração, foi removido o isolamento absoluto e realizado ajuste oclusal com papel carbono (AccuFilm, Parkell, Farmingdale, NY, EUA) e pontas diamantadas para acabamento (KG Sorensen, Cotia, SP, Brasil). As crianças retornaram após sete dias, para polimento final da restauração com pontas abrasivas (Enhance, Dentisply Indústria e Comércio Ltda, Petrópolis, RJ, Brasil).

\subsection{Avaliação do estresse por meio da dosagem de cortisol salivar}

O estresse da criança foi avaliado durante a remoção seletiva das lesões de cárie, por meio da dosagem dos níveis de cortisol salivar.

As amostras de saliva foram coletadas com o sistema Salivette ${ }^{\circledR}$ (Salivette TM, Sarstedt Inc., Nümbrecht, Alemanha), em dois momentos distintos: 1) 7 dias antes dos procedimentos, na própria residência da criança (controle) e 2) durante a remoção das lesões de cárie.

A coleta na residência da criança foi realizada pela mãe ou responsável previamente orientada pelo pesquisador. Foi entregue ao responsável o sistema de coleta Salivette ${ }^{\circledR}$ identificado com os dados da criança, contendo um rolete de algodão amarrado com fio dental e tubo coletor. $O$ rolete de algodão foi colocado na região sublingual da criança 
permanecendo na cavidade bucal por 3 minutos e, na sequência, inserido no tubo coletor e armazenado em geladeira. Os responsáveis pelas crianças foram orientados a evitar a ingestão de alimentos que continham cafeína no dia anterior e no dia das coletas domiciliares e das consultas. Foi recomendado aos pacientes não escovarem os dentes nos trinta minutos que antecediam a coleta da saliva.

Nos dias das consultas, as coletas de saliva foram realizadas pelo pesquisador. 0 rolete de algodão foi colocado na região sublingual da criança permanecendo na cavidade bucal por 3 minutos e, na sequência, inserido no tubo coletor e armazenado em geladeira. As amostras de saliva coletadas deveriam estar transparentes, com baixa viscosidade e sem contaminação com sangue.

As amostras coletadas foram centrifugadas (Biosystems, São José dos Pinhais, Paraná, Brasil) a 3000 RPM por 15 minutos para a extração da saliva e congeladas a $-20^{\circ} \mathrm{C}$ e foram analisadas posteriormente, assim que todas as amostras foram coletadas. A análise dos níveis de cortisol salivar foi realizada em duplicata por meio do teste imunoenzimático (ELISA; Salimetrics Salivary Cortisol ELISA ,USA).

\subsection{Avaliação clínica e fotográfica das restaurações}

Os dentes foram avaliados por meio de análise clínica e fotográfica nos seguintes momentos: 7 dias após a confecção da restauração (após o polimento - baseline), após 6 meses e 1 ano, por três examinadores, seguindo os critérios USPHS modificados (Cvar; Ryge, 2005; Valério et al., 2015), que incluíram a análise da retenção, descoloração marginal, cárie secundária, contorno axial e adaptação marginal. As restaurações foram classificadas em 3 categorias: Alpha - quando o critério avaliado não apresentou problemas e a restauração estava em perfeita condição; Bravo - quando o critério avaliado apresentou pequenas falhas, porém, clinicamente aceitáveis e Charlie - quando o critério avaliado apresentou falhas relevantes e a restauração necessitou ser substituída (Tabela 1). 
Tabela 1 - Critérios USPHS modificados que foram utilizados durante a avaliação das restaurações.

\begin{tabular}{ccc}
\hline Categoria & Escore & Critério \\
\hline \multirow{2}{*}{ Retenção } & Alpha & Sem perda de material restaurador \\
& Charlie & Com perda de material restaurador \\
\hline \multirow{3}{*}{ Descoloração marginal } & Alpha & Sem descoloração marginal \\
& Bravo & Leve descoloração marginal, sem penetração axial \\
& Charlie & Descoloração marginal com penetração axial \\
\hline \multirow{2}{*}{ Cárie secundária } & Alpha & Sem recorrência de cárie \\
& Charlie & Com recorrência de cárie \\
\hline \multirow{2}{*}{ Adaptação marginal } & Alpha & Perfeitamente adaptada, sem margens visíveis \\
& Bravo & Margem visível, porém, clinicamente aceitável \\
& Charlie & Desadaptação marginal, falha clínica \\
\hline \multirow{2}{*}{ Contorno axial } & Alpha & Contínua com a forma dental existente \\
& Bravo & Suavemente com sub contorno ou sobre contorno \\
& Charlie & Sub contorno ou sobre contorno exagerado
\end{tabular}

Foram realizadas fotografias padronizadas dos dentes restaurados por um profissional experiente com maquina digital (Canon EOS Rebel T2i 18.0 Megapixels, Canon, Tóquio, Japão) e lente macro objetiva de 100 mm com flash circular (Canon Macro Ring Lite MR-14EX, Canon, Tóquio, Japão). A qualidade das fotos foi fixada em JPEG FINE e 12,0 megapixels. A câmera foi manipulada no modo manual de operação, ISO 200, F-22, com velocidade de 100 e espaço de cor RGB. Fotografias foram tiradas com os pacientes sentados na cadeira odontológica inclinada para trás para evitar movimentos durante a focagem e fotografia. Um assistente manteve retraída a mucosa da bochecha e os lábios das crianças com afastadores esterilizáveis pediátricos, mantendo a superfície dos dentes decíduos seca. Foi utilizado espelho intrabucal pediátrico mantendo o operador o foco da câmera fotográfica concentrada no centro da restauração. O operador posicionou a câmera fotográfica perpendicular à superfície oclusal, com inclinação não excedendo mais do que $20^{\circ}$ em relação ao plano do molar decíduo, minimizando assim, possíveis reflexos do espelho, o que poderia neutralizar a imagem. Cada fotografia foi avaliada para aceitabilidade e qualidade, caso não aceitável, a fotografia foi repetida. O mesmo examinador que realizou a análise clínica, verificou as fotografias dos molares decíduos restaurados em um monitor de tela plana de alta resolução e pode comparar os dados obtidos na análise clínica com os da fotográfica chegando assim a um resultado preciso. 


\subsection{Avaliação da adaptação marginal da réplica das restaurações}

Após o período de 7 dias, 6 e 12 meses da confecção da restauração, os dentes foram moldados com moldeiras parciais perfuradas de alumínio (Golgran Ind. Odontológica, São Paulo, SP, Brasil) e silicona de adição (Express XT, 3M ESPE, Germany). As moldagens, após serem desinfectadas com solução de clorexidina a $2 \%$, foram vazadas com resina epóxi (Buehler, SC, Brasil). As réplicas das restaurações obtidas foram fixadas em stubs de alumínio com fita carbono dupla face, metalizadas com fina cobertura de ouro e analisadas em MEV (Zeiss, EVO 50, Cambridge, Reino Unido) com 20x de aumento.

As análises foram realizadas por um examinador com experiência em microscopia eletrônica de varredura que desconhecia os métodos de remoção de lesão de cárie utilizados. Os artefatos do modelo foram desconsiderados.

Figura 1- Desenho experimental do estudo.

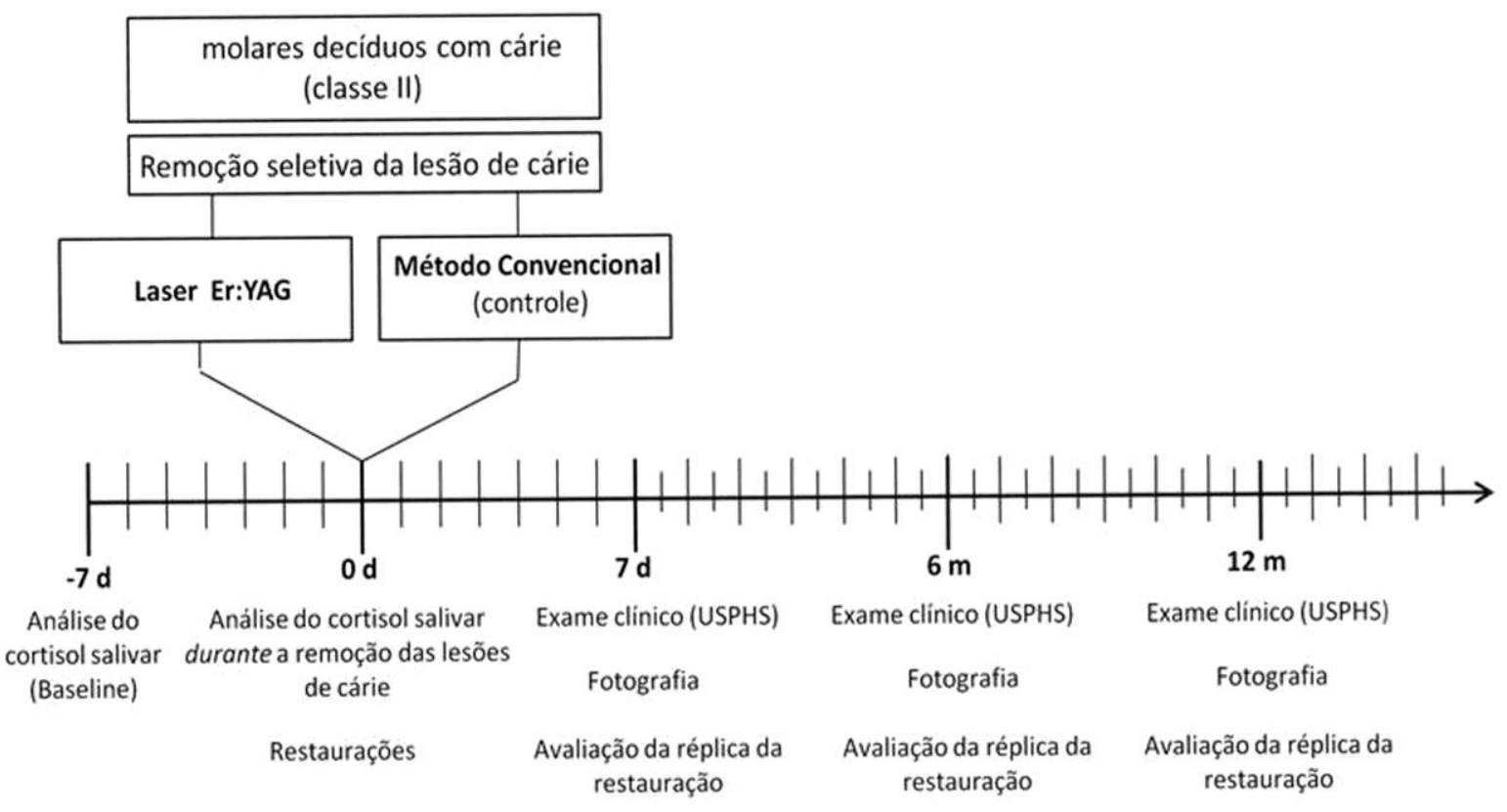


Figura 2- CONSORT= esquema explicativo do recrutamento, atribuição, acompanhamento e análise de dados final.

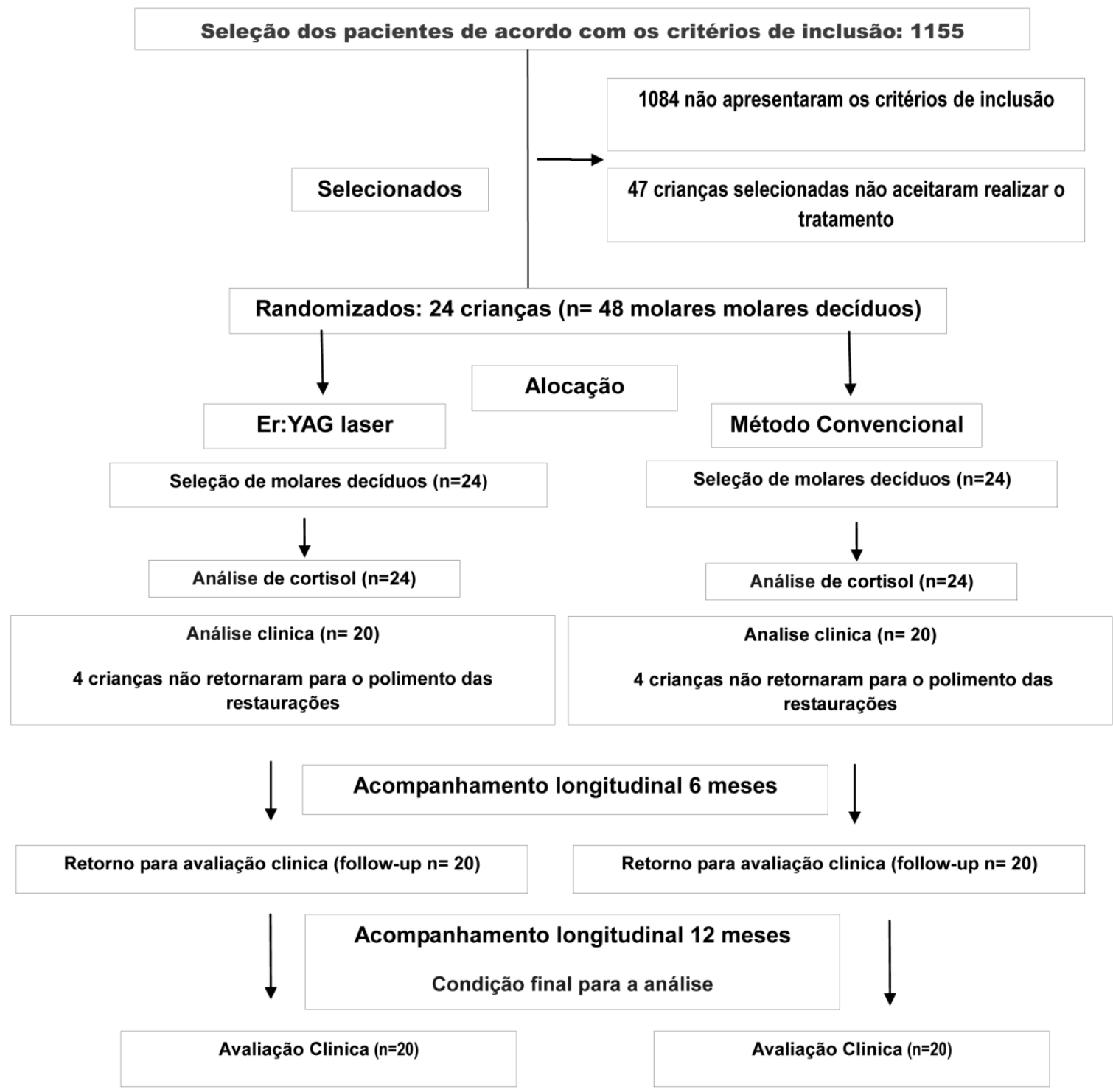

\subsection{Análise estatística}

Os dados obtidos pela análise de cortisol salivar foram estatisticamente analisados pelo teste ANOVA. As comparações múltiplas foram realizadas usando o teste de Tukey a um nível de significância de 5\%. A análise estatística foi feita com o software SPSS para Windows, versão 19.0 (SPSS Inc., Chicago, IL, EUA).

Para análise dos critérios USPHS, foi realizada estatística descritiva e os intervalos de 95\% de confiança foram construídos para proporções dos resultados obtidos. 

4. Resultados 



\section{RESUltados}

A tabela 2 mostra a presença de diferença estatística nos níveis de cortisol salivar nos períodos avaliados $(p=0,05)$. Os níveis de cortisol salivar foram maiores durante a remoção da lesão de cárie, independente do método utilizado. Os níveis de cortisol salivar obtidos durante a remoção da lesão de cárie com laser de Er:YAG foram semelhantes aos obtidos com o método convencional

Tabela 2- Níveis de cortisol salivar ( $\mathrm{nmol} / \mathrm{L}$ ) obtidos durante a remoção seletiva da lesão de cárie, em cavidades de classe II de molares decíduos $(n=24)$.

\begin{tabular}{lc}
\hline Período de Coleta do Cortisol Salivar & $\begin{array}{c}\text { Nível de Cortisol Salivar } \\
\text { (nmol/L) média } \pm \text { DP }\end{array}$ \\
\hline Antes do procedimento (baseline) & $0,759 \pm 0,571 b$ \\
Durante a remoção seletiva da lesão de cárie com laser de Er:YAG & $2,253 \pm 1,427 a$ \\
Durante a remoção seletiva da lesão de cárie com método convencional & $2,705 \pm 1,842 a$ \\
\hline
\end{tabular}
Letras iguais indicam similaridade estatística $(p=0,05)$.

\subsection{Avaliação clínica e fotográfica das restaurações}

Na avaliação clínica 7 dias após a confecção (baseline) todas as restaurações receberam o escore Alpha para as 4 categorias analisadas.

A análise clínica das restaurações de classe II foi realizada utilizando os critérios USPHS modificados. O teste Tnão encontrou evidência de diferença para a retenção, adaptação marginal, descoloração, contorno axial e cárie secundária para as restaurações realizadas em cavidades preparadas por ambos os métodos. Na análise dos 12 meses, uma restauração preparada com o método convencional foi perdida.

A figura 3 representa as lesões de cárie ativa em molares decíduos e as restaurações finalizadas nos períodos inicial, 6 meses e 1 ano. 
Figura 3- Remoção da cárie utilizando método convencional (A) ou laser Er:YAG (B). A1: lesão de cárie ativa nas superfícies oclusal e proximal de molar decíduo, A2: aspecto inicial da restauração (baseline), A3: restauração após 6 meses, A4: restauração após 12 meses. B1: lesão de cárie ativa nas superfícies oclusal e proximal de molar decíduo; B2: aspecto inicial da restauração ( baseline), B3: restauração após 6 meses; B4: a restauração após 12 meses.
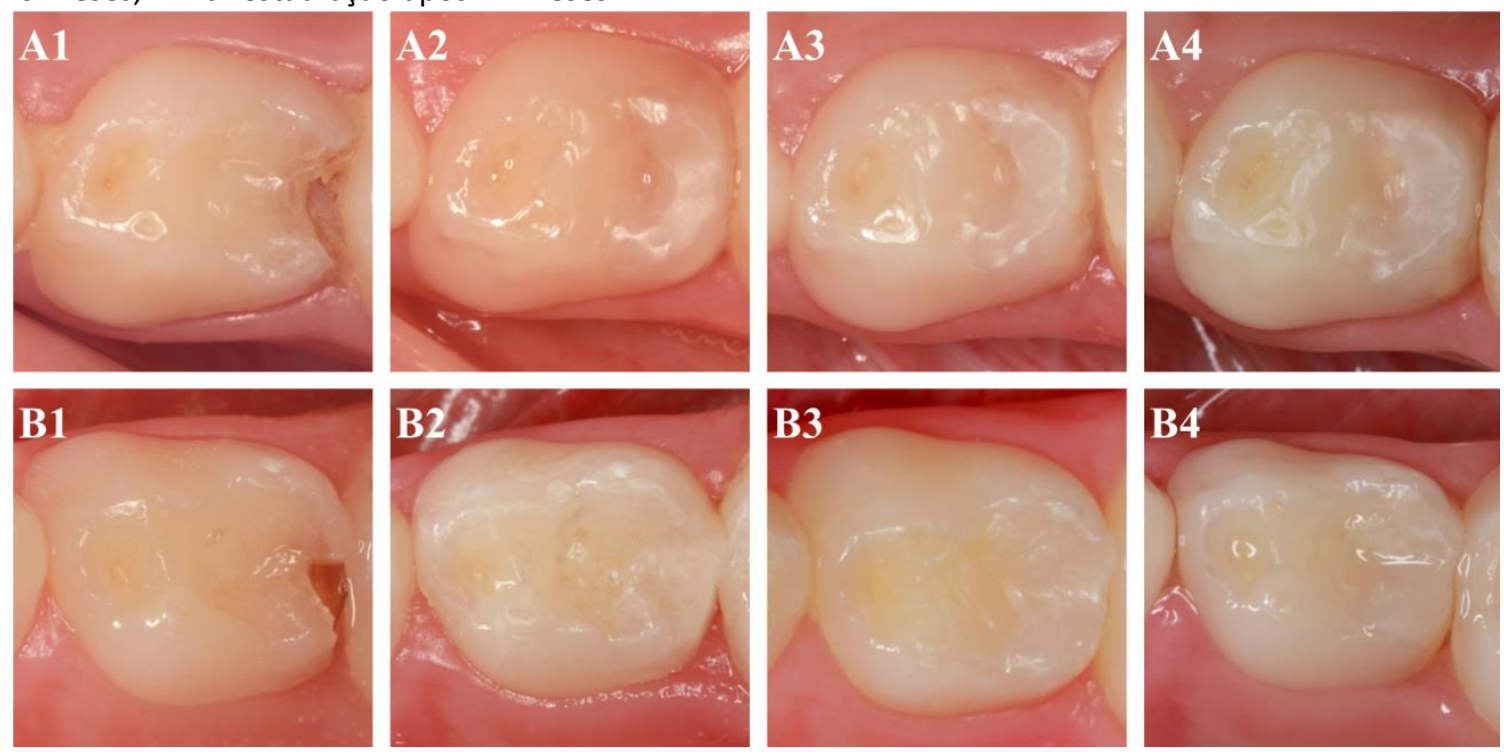
Tabela 3- Resultados da análise clínica das restaurações de classe II utilizando-se o critério USPHS modificado

\begin{tabular}{|c|c|c|c|c|c|c|c|c|c|c|c|c|c|c|c|c|c|}
\hline \multirow{2}{*}{ Tratamento } & \multirow{2}{*}{$\begin{array}{l}\text { Avaliação } \\
\text { Período }\end{array}$} & & \multicolumn{3}{|c|}{ Retenção } & \multicolumn{3}{|c|}{ Descoloração } & \multicolumn{3}{|c|}{ Adaptação Marginal } & \multicolumn{3}{|c|}{ Contorno axial } & \multicolumn{3}{|c|}{ Cárie secundária } \\
\hline & & & *A & B & C & A & B & C & A & B & C & A & B & C & A & B & C \\
\hline \multirow{9}{*}{$\begin{array}{c}\text { Método } \\
\text { Convencional }\end{array}$} & Baseline & $\mathrm{n}=20$ & 20 & - & - & 20 & - & - & 20 & - & - & 20 & - & - & 20 & - & - \\
\hline & & $(\%)$ & $(100)$ & - & - & $(100)$ & - & - & $(100)$ & - & - & $(100)$ & - & - & $(100)$ & - & - \\
\hline & & $\begin{array}{c}95 \% \\
\mathrm{Cl}\end{array}$ & - & - & - & - & - & - & - & - & - & - & - & - & - & - & - \\
\hline & 6 meses & $n=20$ & 20 & - & - & 20 & - & - & 19 & 1 & - & 20 & - & - & 20 & - & - \\
\hline & & $(\%)$ & $(100)$ & - & - & $(100)$ & - & - & (95) & (5) & - & $(100)$ & - & - & $(100)$ & - & - \\
\hline & & $\begin{array}{c}95 \% \\
\mathrm{Cl}\end{array}$ & - & - & - & - & - & - & $85.44-100.00$ & $0-14.55$ & - & - & - & - & - & - & - \\
\hline & 12 meses & $n=20$ & 19 & - & 1 & 20 & - & - & 19 & 1 & - & 20 & - & - & 20 & - & - \\
\hline & & $(\%)$ & (95) & - & (5) & $(100)$ & - & - & (95) & (5) & - & $(100)$ & - & - & $(100)$ & - & - \\
\hline & & $95 \% \mathrm{Cl}$ & $85.44-100.00$ & - & $0-14.55$ & - & - & - & $85.44-100.00$ & $0-14.55$ & - & - & - & - & - & - & - \\
\hline \multirow{9}{*}{$\begin{array}{l}\text { Laser } \\
\text { Er:YAG }\end{array}$} & Baseline & $n=20$ & 20 & - & - & 20 & - & - & 20 & - & - & 20 & - & - & 20 & - & - \\
\hline & & (\%) & $(100)$ & - & - & $(100)$ & - & - & $(100)$ & - & - & $(100)$ & - & - & $(100)$ & - & - \\
\hline & & $95 \% \mathrm{Cl}$ & - & - & - & - & - & - & - & - & - & - & - & - & - & - & - \\
\hline & 6 meses & $n=20$ & 20 & - & - & 20 & - & - & 20 & - & - & 20 & - & - & 20 & - & - \\
\hline & & $(\%)$ & $(100)$ & - & - & $(100)$ & - & - & $(100)$ & - & - & $(100)$ & - & - & (100) & - & - \\
\hline & & $95 \% \mathrm{Cl}$ & - & - & - & - & - & - & - & - & - & - & - & - & - & - & - \\
\hline & 12 meses & $n=20$ & 20 & - & - & 20 & - & - & 19 & - & 1 & 20 & - & - & 20 & - & - \\
\hline & & (\%) & (100) & - & - & (100) & - & - & (95) & - & (5) & $(100)$ & - & - & (100) & - & - \\
\hline & & $95 \% \mathrm{Cl}$ & - & - & - & - & - & - & $85.44-100.00$ & - & $0-14.55$ & - & - & - & - & - & - \\
\hline
\end{tabular}

*representa os escores $A=A / p h a, B=B$ ravo e $C=$ Charlie. 


\subsection{Avaliação da adaptação marginal da réplica das restaurações}

A adaptação marginal das restaurações foi realizada por meio da análise da réplica das restaurações analisadas por MEV. A análise quantitativa revelou que os dentes irradiados por laser apresentaram $10 \%$ de fendas em toda a extensão da restauração. Para aqueles dentes preparados com método convencional, foram encontrados $20 \%$ de fendas no ângulo cavo (Figura 4).

Figura 4- Microscopia eletrônica de varredura das restaurações realizadas em cavidades preparadas pelo método convencional $(A)$ ou laser Er:YAG (B). A1: restauração inicial; A2: restauração após 6 meses; A3: restauração após 12 meses. B1: restauração inicial; B2: restauração após 6 meses; B3: restauração após 12 meses. A seta indica a interface adesiva.
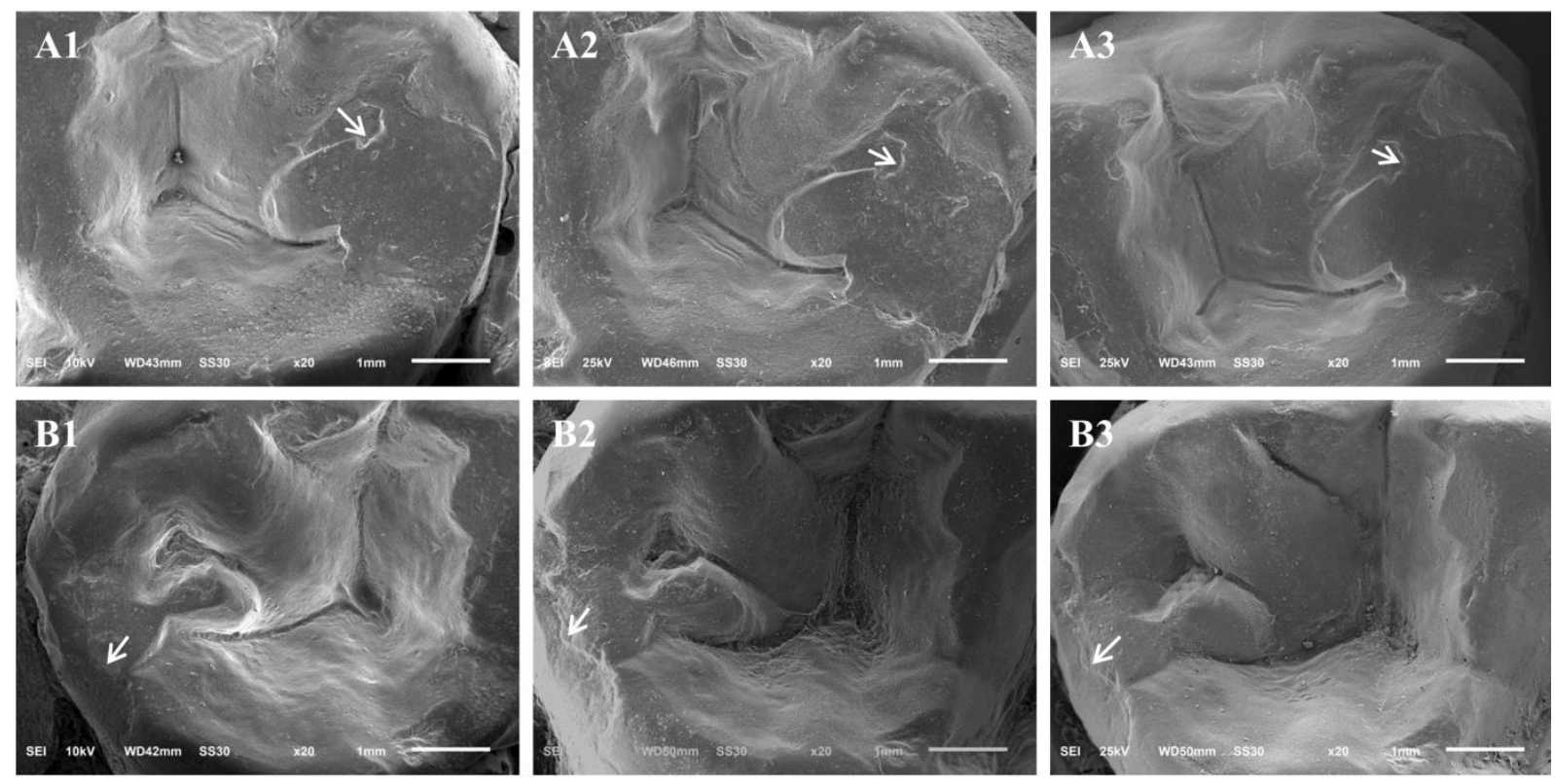


\section{5. $D_{\text {iscussão }}$}





\section{DiscUSSÃo}

No presente estudo, a hipótese nula que os níveis de cortisol salivar seriam semelhantes durante a remoção seletiva da lesão de cárie, utilizando o método convencional ou o laser de Er:YAG, foi aceita.

Os níveis de cortisol salivar obtidos antes do tratamento odontológico (baseline) apresentaram-se inferiores estatisticamente aos obtidos durante a remoção seletiva da lesão de cárie. Esses resultados corroboram com os encontrados por Yfanti et al., 2014 e Kandemir et al,. 1997, onde o tratamento odontológico também estimulou o eixo HipotálamoPituitária-Adrenal, promovendo aumento dos níveis de cortisol salivar durante a remoção de lesões de cárie. Os níveis basais de cortisol salivar, obtidos no presente estudo foram comparáveis aos níveis normais obtidos no estudo de Mc McCarthy et al., 2009, que analisou os níveis de cortisol de crianças da faixa etária de 4 a 10 anos.

O laser de Er:YAG remove a dentina cariada por meio de processo ablativo, onde o feixe de laser promove um impacto de energia na camada hidratada, levando à micro explosão e evaporação instantânea dessa água . Desta forma, consegue-se a remoção tecidual sem transferir calor (aquecimento) aos tecidos remanescentes, promovendo uma adequação cavitária sem contato mecânico com o substrato dental, esse processo não promove vibração ou pressão durante a remoção da lesão de cárie, proporcionando conforto as crianças (Valério et.al, 2015).

Neste estudo, no método convencional utilizou-se um motor elétrico, com sistema de indução eletromagnética, apresentando 40.000 RPM e torque de $2.5 \mathrm{~N} . \mathrm{cm}$, diferindo do micro motor convencional que apresenta sistema pneumático com 20.000 RPM e o torque de 1.2 N.cm, possibilitando remoção da lesão com menor pressão e ruído.

Os resultados deste estudo sugerem que o procedimento de remoção de lesões de cárie pode causar aumento do nível de cortisol na criança e não os diferentes métodos de remoção da lesão de cárie. O conhecimento desse momento mais estressante pode ser útil para o dentista a fim de que possa preparar a criança. Este aspecto também foi encontrado no trabalho de Akyuz et al., 1996.

Outro aspecto a ser considerado é a técnica utilizada para a remoção das lesões de cárie. A remoção seletiva de tecido dentário cariado em dentes decíduos tem como vantagens remover o mínimo possível de estrutura dentária remanescente sadia, evitando 
exposições pulpares (Ricketts et al., 2006; Thompson et al., 2008; Schwendicke et al.,2016), principalmente em dentes decíduos que apresentam menor porção mineral (De Menezes Oliveira et al., 2010), uma vez que, a dentina afetada que permanece nas paredes pulpar e axial da cavidade preparada é passível de remineralização (Kidd, 2004; Maltz et al., 2007; Thompson et al., 2008; Maltz et al., 2012).

Todos os pacientes foram anestesiados, proporcionando maior conforto durante o tratamento, evitando dores leves e moderadas que poderiam elevar os níveis de cortisol (Davis et al., 1999; Dettling et al., 1999) e somente após 20 minutos da aplicação da anestesia infiltrativa é que se iniciou a remoção da lesão de cárie. A dor aguda pode aumentar os níveis de cortisol (King \& Hegadoren, 2002), uma vez que é um agente estressante. Dependendo do estímulo doloroso aplicado, pode até mesmo quadruplicar o nível da concentração do cortisol (Zimmer et al., 2003). Embora não haja diferença entre a média da concentração de cortisol salivar e o grau de ansiedade, a mensuração do cortisol salivar é diferente para os pacientes que têm dor e os que não têm dor.

Outro fator que pode ter contribuído para a ausência da diferença dos níveis de cortisol entre os métodos de remoção da lesão de cárie pode ser o fato de poucas crianças terem exibido um comportamento ansioso, ao contrario, a maioria respondeu positivamente, com sorrisos e comportamentos de aproximação e consentimento para ambos os tratamentos, mesmo que o laser fosse novidade para todos os participantes.

Nesse estudo, utilizamos a avaliação dos níveis de cortisol salivar para analisar respostas ao estresse em crianças durante a remoção de lesões de cárie, embora existam outras medidas fisiológicas (incluindo a frequência cardíaca, saturação de oxigênio, pressão arterial, tônus vagal, glicose, catecolaminas e outros hormônios), essas medidas possuem aspectos invasivos e podem não apresentar especificidade para a resposta ao estresse durante os procedimentos avaliados. Em muitos casos, não é viável a coleta de sangue, por vezes, é ainda indesejável especialmente em pacientes infantis. A avaliação do cortisol salivar oferece a oportunidade de coletar as amostras sem o estímulo do estresse para as análises de cortisol basal (baseline), sem a presença do pessoal da área médica e, em muitos ambientes diferentes conferindo maior fidelidade de valores basais às amostras (Jessop e Turner-Cobb, 2008).

A técnica de avaliação dos níveis de cortisol salivar que utilizamos nesse estudo se mostrou objetiva, não invasiva, segura e altamente específica para as medições do estresse, 
estando de acordo com os estudos de McCarthy et al., 2007, que estabeleceram valores de cortisol salivar normais e valores de responsividade a estressores específicos em crianças com idade entre 4 e 10 anos.

O método de análise imunoenzimático em duplicata utilizado neste trabalho foi bastante prático e de fácil manipulação. Os resultados obtidos mostram que as curvas padrão dos ensaios realizados apresentam coeficientes de determinação próximos, demonstrando boa replicabilidade.

A hipótese nula testada de que o método de remoção seletiva da lesão de cárie não influencia no comportamento longitudinal das restaurações de resina composta classe II em dentes decíduos, foi aceita. Os resultados deste estudo não apresentaram diferenças nos critérios avaliados (retenção, descoloração marginal, cárie secundaria, contorno axial e adaptação marginal) independente do método de remoção seletiva da lesão de cárie, de acordo com o critério USPHS modificado e a análise fotográfica após um ano. Isto pode ter ocorrido, devido ao fato de ambos os métodos de remoção da lesão de cárie promoverem adequado vedamento da cavidade (Valério et al., 2015; Galafassi et al., 2017). A utilização dos critérios do Serviço de Saúde Pública dos Estados Unidos (USPHS) modificados que utilizamos nesse trabalho é usado na maioria dos estudos clínicos para avaliar o sucesso clínico da restauração de acordo com os estudos de van Dijken e Pallesen (van Dijken \& Pallesen, 2011). O sucesso do tratamento minimamente invasivo se dá pela habilidade do material restaurador em promover selamento apropriado da dentina, mantendo-o intacto e aderido à superfície dental ao longo do tempo (Samad-Zadeh et al., 2011). O emprego do laser de Er:YAG para a remoção da lesão de cárie também apresentou resultados semelhantes ao método convencional em cavidades de classe I (Valério et al., 2015). De acordo com Hamidi et al., 2015, as restaurações avaliadas demonstraram uma performance clínica aceitável dentro do período de avaliação ( 5 anos) com base na avaliação USPHS, no entanto esse estudo apresentou limitações metodológicas, pois não havia nenhum grupo de comparação como cavidades preparadas com método convencional, as restaurações foram, feitas em cavidades preparadas apenas com laser de Er:YAG, onde o método de remoção a laser forneceu restaurações de longa duração. Franzon et al., 2015, demonstraram que as restaurações de resina composta em molares decíduos cariados apresentaram uma sobrevida aceitável de 76\% após 2 anos de acompanhamento onde a técnica de remoção de cárie seletiva resultou também em menos exposições pulpares. 
Com o objetivo de analisar a vedação marginal da restauração, a presença de irregularidades e fendas, as restaurações foram moldadas usando silicona de adição (Willians et al., 1984) e vazadas com resina epóxi, sendo possível analisar as características originais da restauração sob ampliação de 20x. A análise da réplica da restauração por meio de MEV apresentou $10 \%$ de fendas em toda a extensão da restauração quando a remoção seletiva da lesão de cárie foi realizada com laser de Er:YAG e 20\% de fendas localizadas no ângulo cavo superficial proximal quando da utilização do método convencional, esses resultados demonstraram que ambas as técnicas foram eficazes, pois as fendas foram detectadas em porcentagem pequena das restaurações, e quando do emprego do laser de Er:YAG a porcentagem de fendas foi menor. Puppin-Rontani et al., 2006, observaram restaurações de classe II em dentes decíduos, bem adaptadas á dentina após 18 meses da realização, utilizando o método indireto de avaliação e utilizando estereomicroscópio , para as análises dos modelos. De acordo com o trabalho de Garcia-Godoy e colaboradores, que após 6 anos de avaliação clinica encontraram de 74 a 80 \% de fendas nas restaurações realizadas, a avaliação indireta das restaurações por meio de MEV permite uma quantificação precisa, além de ser um método bem conhecido para a avaliação de restaurações adesivas e pode ser considerada a configuração mais próxima da situação clínica (Garcia-Godoy et. al, 2010).

No geral, observamos que o laser de Er:YAG promove um tratamento conservador na remoção de cárie por conta da elevada absorção no tecido cariado (Bohari et al., 2012). Isto permite a mínima escavação de lesões de cárie, sem estender o preparo em estrutura dentaria sadia ( Baraba et al.,2012). Além disso, não gera o ruído, vibração ou pressão (Keller \& Hibst 1997; Bohari et al., 2012), tornando o tratamento dentário menos traumático, especialmente para as crianças. Os pacientes demonstraram uma percepção reduzida da dor durante o tratamento com o laser (Bohari et al., 2012) e, dessa forma, há uma redução na utilização da anestesia local infiltrativa (Keller \& Hibst 1997; Krause et al., 2008). O tratamento a laser é, portanto, muitas vezes preferido pelos pacientes (Samadi et al., 2014; Polizeli et.al, 2016) e pode ser um método alternativo em relação ao método convencional. 
6. Conclusão 



\section{CONCLUSÃo}

Com base nos resultados obtidos, concluímos que:

- O laser de Er:YAG pode ser usado para a remoção de lesões de cárie e sua utilização não promove o aumento de níveis salivares de cortisol em crianças.

- O laser de Er:YAG pode ser usado para a remoção de cárie em molares decíduos, sem influenciar o desempenho clínico das restaurações de resina composta classe II, após 1 ano de acompanhamento clínico. 

Referências 



\section{REFERÊNCIAS}

Abreu DM, Leal SC, Frencken JE. Pain experience after conventional, a traumatic, and ultraconservative restorative treatments in 6- to 7-yr-old children. Eur J Oral Sci. 2011;119:163-8.

Akyuz S, Pince S, Hekin N. Children's stress during a restorative dental treatment: assessment using salivary cortisol measurements. J Clin Pediatr Dent. 1996 Spring;20(3):219-23.

Aoki A, Ishikawa I, Yamada T, Otsuki M, Watanabe H, Tagami J, et al. Comparison between Er:YAG laser and conventional technique for root cáries treatment in vitro. J Dent Res. 1998;77(6):1404-14.

Armengol V, Jean A, Marion D. Temperature rise during Er:YAG and Nd:YAP laser ablation of dentin. J Endod. 2000;26(3):138-41.

Baraba A, Perhavec T, Chieffi N, Ferrari M, Anić I, Miletić I. Ablative potential of four different pulses of Er:YAG lasers and low-speed hand piece. Photomed Laser Surg. 2012 Jun;30(6):3017.

Benjamin SD. Dental laser: part 3. Use of dental lasers on hard tissue. Pract Proced Aesthet Dent. 2002;14(5):422-4.

Bohari MR, Chunawalla YK, Ahmed BM. Clínical evaluation of cáries removal in primary teeth using conventional, chemomechanical and laser technique: an in vivo study. J Contemp Dent Pract. $2012,13(1): 40-7$.

Cenci MS, Lund RG, Pereira CL, de Carvalho RM, Demarco FF. In vivo and in vitro evaluation of Class II composite resin restorations with different matrix systems. J Adhes Dent. 2006;8(2):127-132.

Chapman HR, Kirby-Tumer NC. Dental fear in children- a proposed model.Br Dent J 2000;187(8):175-80.

Corona SAM, Borsatto MC, Palma-Dibb RG, Ramos RP Jr, Brugnera A, Pécora JD. Microleakage of class $\mathrm{V}$ resin composite restorations after bur, Air-abrasion or Er:YAG laser preparition. Oper Dent. 2001;26(5):491-7.

Correa BC, Galo R, Scatena C, Borsatto MC, Spazzin AO, Corona SA, Galafassi D.Effect of Metalloproteinase Inhibitors on the Microtensile Bond Strength ofComposite Resin to Er:YAG Laser-Irradiated Dentin. Braz Dent J. 2016 Jul-Aug;27(4):442-5.

Cozean C, Arcoria CJ, Pelagalli J, Powel MGL. Dentistry for the 21th century?Erbuim: YAG laser forteeth. J Am Dent Assoc. 1997;128(8):1080-7.

Croll TP. Restorative dentistry for preschool children. Dent Clin North Am. 1995 Oct;39(4):737-70. 
Cvar JF, Ryge G. Reprint of criteria for the clínical evaluation of dental restorative materials. 1971.Clin Oral Investig. 2005 Dec;9(4):215-32.

Davis EP, Donzella B, Krueger WK, Gunnar MR. The start of a new school year: individual differences in salivary cortisol response in relation to child temperament. Dev Psychobiol. 1999 Nov;35(3):188-96.

De Menezes Oliveira MA, Torres CP, Gomes-Silva JM, Chinelatti MA, De Menezes FC, PalmaDibb RG, Borsatto MC. Microstructure and mineral composition of dental enamel of permanent and decíduous teeth. Microsc Res Tech. 2010 May;73(5):572-7.

Dettling AC, Gunnar MR, Donzella B. Cortisol levels of young children in full-day childcare centers: relations with age and temperament. Psychoneuroendocrinology. 1999 Jul;24(5):519-36.

Dommisch H, Peus K, Kneist S, Krause F, Braun A, Hedderich J et al.. Fluorescence-controlled laser for cáries removal in permanent teeth: a randomized clínical trial. Eur J Oral Sci. 2008;116(2):170-6.

Evans DJ, Mathews S, Pitts NB. A clínical evaluation of an erbium:YAG laser ablation: a preliminary evaluation of human teeth. J Clin Laser Med Surg. 2000;15:117-21.

Franzon R, Opdam NJ, Guimarães LF, Demarco FF, Casagrande L, Haas AN, Araujo FB. Randomized controlled clínical trial of the 24-months survival of composite resin restorations after one-step incomplete and complete excavation on primary teeth. J Dent. 2015 Oct;43(10):1235-41.

Furlan NF, Gavião MB, Barbosa TS, Nicolau J, Castelo PM. Salivary cortisol, alpha-amylase and heart rate variation in response to dental treatment in children. J ClinPediatr Dent. 2012 Fall;37(1):83-7.

Fusayama T. Two layers of carious dentin; diagnosis and treatment. Oper Dent. 1979;4(2):6370.

Galafassi D, Scatena C, Galo R, Curylofo-Zotti FA, Corona SAM, Borsatto MC. Clínical evaluation of composite restorations in Er:YAG laser-prepared cavities re-wetting with chlorhexidine. Clin Oral Investig. 2017 May;21(4):1231-1241.

Ganong BR. Roles of lipid turnover in transmembrane signal transduction. Am J Med Sci. 1991 Nov;302(5):304-12. Review.

Garcia-Godoy F, Krämer N, Feilzer AJ, Frankenberger R. Long-term degradation of enamel and dentin bonds: 6-year results in vitro vs. in vivo.Dent Mater. 2010 ;26(11):1113-8.

Guler C, Malkoc MA, Gorgen VA, Dilber E, Bulbul M. Effects of Er:YAG laser on mineral content of sound dentin in primary teeth. ScientificWorldJournal. 2014;2014:578342.

Hamidi MM, Ercan E, Dülgergil ÇT, Çolak H. Evaluation of the clínical success of class I cavities prepared by an Er:YAG laser-5-year follow-up study. Lasers Med Sci. 2015 Sep; 30(7). 
Hanrahan K, McCarthy AM, Kleiber C, Lutgendorf S, Tsalikian E. Strategies for salivary cortisol collection and analysis in research with children. Appl Nurs Res. 2006 May;19(2):95-101. Review.

Hibst R, Keller U. Experimental studies of the application of the Er:YAG laser on dental hard subs-tances: I. Measurement of the ablation rate. Lasers Surg Med. 1989; 9:338-4.

Hugo B, Stassinakis A. Preparation and restoration of small interproximal carious lesions with sonic instruments. Pract Periodont Aesthet Dent. 1998;10(3):353-9.

Jacobson B, Asgari A. Restorative dentistry for children using a hard tissue laser. Alpha Omegan. 2008;101(3):133-9.

Jafarzadeh M, Arman S, Pour FF. Effect of aromatherapy with orange essential oil on salivary cortisol and pulse rate in childrenduring dental treatment: $A$ randomized controlled clínical trial.Adv Biomed Res. 2013; 2:10.

Jessop DS, Turner-Cobb JM. Measurement and meaning of salivary cortisol: afocus on health and disease in children. Stress. 2008 Jan;11(1):1-14. Epub 2007 Jul 16. Review.

Kambalimath HV, Dixit UB, Thyagi PS. Salivary cortisol response to psychological stress in children with early childhood cáries. Indian J Dent Res. 2010 Apr-Jun;21(2):231-7.

Kandemir S, Ok'lan T, Alpфz AR, Ergezer G, Kabalak T. Salivary cortisol levels in children during dental treatment. J Marmara Univ Dent Fac 1997;2:639-42.

Kato J, Moriya K, Jayawardena JA, Wijeyeweera RL. Clínical application of Er:YAG laser for cavity preparation in children. J Clin Laser Med Surg. 2003;21:151-5.

Keller U, Hibst R. Effects of Er:YAG Laser in cáries treatment: a clínical pilot study. Lasers Surg Med. 1997; 20:32-8.

Keller U, Hibst R, Geurtsen W, Schilke R, Heidemann D, Klaiber B, et al. Erbium: YAG laser application in cáries therapy. Evaluation of patient perception and acceptance. J Dent. 1998; 26(8):649-56.

Keil MF. Salivary cortisol: a tool for biobehavioral research in children. J Pediatr Nurs. 2012 Jun;27(3):287-9. doi: 10.1016/j.pedn.2012.02.003. Epub 2012, Mar 8.

Kidd EAM. How clean must a cavity be before restoration? Cáries Res. 2004;38:305-13.

King SL, Hegadoren KM. Stress hormones: how do they measure up? Biol Res Nurs.2002 Oct;4(2):92-103. Review.

Kornblit R, Trapani D, Bossu M, Muller-Bolla M, Rocca JP, Polimeni A. The use of Erbium:YAG laser for cáries removal in paediatric patients following Minimallylnvasive Dentistry concepts. Eur J Paediatr Dent. 2008 Jun;9(2):81-7. 
Krause F, Braun A, Lotz G, Kneist S, Jepsen S, Eberhard J. Evaluation of selective cáries removal in decíduous teeth by a fluorescence feedback-controlled Er:YAG laser in vivo. Clin Oral Invest. 2008;12:209-15.

Léda L, Azevedo TD, Pimentel PA, de Toledo OA, Bezerra AC. Dentin Optical Density in Molars Subjected to Partial Carious Dentin Removal. J Clin Pediatr Dent. 2015 Fall;39(5):452-7.

Liu JF, Lai YL, Shu WY, Lee SY. Acceptance and efficiency of Er:YAG laser for cavity preparation in children. Photomed Laser Surg. 2006;24(4):489-93.

McCarthy AM, Hanrahan K, Kleiber C, Zimmerman MB, Lutgendorf S, Tsalikian E.Normative salivary cortisol values and responsivity in children. Appl Nurs Res. 2009 Feb;22(1):54-62.

Maltz $M$, Oliveira EF, Fontanella $V$, CarminattiG. Deep cáries lesions after incomplete dentine cáries removal: 40-month follow-up study. Cáries Res. 2007; 41(6):493-6.

Maltz M, Jardim JJ, Mestrinho HD, Yamaguti PM, Podestá K, Moura MS, de Paula LM. Partial removal of carious dentine: a multicenter randomized controlled trial and 18-month followup results. Cáries Res. 2013;47(2):103-9.

MassaraMI, Alves JB, Brandao PR. A traumatic restorative treatment: clínical,ultrastructural and chemical analysis. Cáries Res. 2002; 36: 430-6.

Montedori A, Abraha I, Orso M, D'Errico PG, Pagano S, Lombardo G. Lasers for cáries removal in decíduous and permanent teeth. Cochrane Database Syst Rev. 2016, Sep 26;9:CD010229. [Epub ahead of print] Review.

Moore PA, Hersh EV. Local anesthetics: pharmacology and toxicity. Dent Clin North Am. 2010 Oct;54(4):587-99.

Mosskull HP, Bågesund M. Er:YAG laser or high-speed bur for cavity preparation in adolescents.ActaOdontolScand. 2012.

O'Connell AC. The partial removal of carious tissue may arrest cáriesprogression in primary teeth. J Evid Based Dent Pract. 2012 Sep;12(3):146-8. doi:10.1016/j.jebdp.2012.06.011. PubMed PMID: 22935281.

Paghdiwala AF. Does the laser work on hard dental tissue? JADA. 1991;122:79-80.

Patil SJ, Shah PP, Patil JA, Shigli A, Patil AT, Tamagond SB. Assessment of the changes in the stress-related salivary cortisol levels to the various dental procedures in children. J Indian SocPedodPrev Dent. 2015 Apr-Jun; 33(2):94-9.

Pelagalli J, Gimbel C B, Hansen Rt, Swett A, Winn, D W. Investigational study of the use of EnYAG laser versus dental drill for cáries removal and cavity preparation-Phase I. J. Clin, Laser Med. Surg., 15(3):109-15,1997.

Pimenta RA, Penido CV, Cruz Rde A, Alves JB. Morphology of the dentin on primary molars after the application of phosphoric acid under different conditions. Braz Oral Res. 2010 JulSep;24(3):323-8. 
Polizeli, S. A. F., Valério, R. A., Nemezio, M. A., Galo, R., Rodrigues-Júnior, A. L., \& Corona, S. A. M. Sensitivity evaluation of cáries removal in primary molars using an ER:YAG laser: a randomized split-mouth clínical trial. EJPMR, 2016,3(8), 116-122.

Puppin-Rontani RM, de Góes MF, Voelske CE, García-Godoy F. Clínicalperformance and SEM evaluation of direct composite restorations in primary molars. Am J Dent. 2006 Oct;19(5):255-61.

Queiroz AM, Carvalho AB, Censi LL, Cardoso CL, Leite-Panissi CR, da Silva RA, de Carvalho FK, Nelson-Filho $P$, da Silva LA. Stress and anxiety in children after the use of computerized dental anesthesia. Braz Dent J. 2015 May-Jun;26(3):303-7.

Ram D, Hermida LB, Peretz B. A comparison of warmed and room-temperature anesthetic for local anesthesia in children. Pediatr Dent. 2002 Jul-Aug;24(4):333-6.

Ribeiro CC, de Oliveira Lula EC, da Costa RC, Nunes AM. Rationale for the partial removal of carious tissue in primary teeth. Pediatr Dent. 2012 Jan-Feb;34(1):39-41.

Ricketts DN, Kidd EA, Innes N, Clarkson J. Complete or ultraconservative removal of decayed tissue in unfilled teeth. Cochrane Database Syst Rev. 2006.

Ricketts D, Lamont T, Innes NP, Kidd E, Clarkson JE. Operative cáries management in adults and children. Cochrane Database Syst Rev. 2013.

Samad-Zadeh A, Harsono M, Belikov A, Shatilova KV, Skripnik A, Stark P, Egles C, Kugel G. The influence of laser-textured dentinal surface on bond strength.Dent Mater. 2011 Oct;27(10):1038-44.

Sarmadi R, Hedman E, Gabre P. Laser in cáries treatment--patients' experiences and opinions. Int J Dent Hyg. 2014 Feb;12(1):67-73.

Schwendicke F, Dörfer CE, Paris S. Incomplete cáries removal: a systematic review and metaanalysis. J Dent Res. 2013 Apr;92(4):306-14.

Schwendicke F, Frencken JE, Bjørndal L, Maltz M, Manton DJ, Ricketts D, Van Landuyt K, Banerjee A, Campus G, Doméjean S, Fontana M, Leal S, Lo E, Machiulskiene V, Schulte A, Splieth C, Zandona AF, Innes NP. Managing Carious Lesions: Consensus Recommendations on Carious Tissue Removal. Adv Dent Res. 2016 May;28(2):58-67.

Shah B, Ashok L, Sujatha G P. Evaluation of salivary cortisol and psychological factors in patients with oral lichen planus. Indian J Dent Res 2009;20:288-92.

Singh RK, Kumar A, Singh S.Child anxiety.Br Dent J. 2009;206 10):507.

Soares FC, Lima RA, Santos Cda F, de Barros MV, Colares V. Predictors of dental anxiety in Brazilian 5-7years old children. Compr Psychiatry. 2016. May;67:46-53.doi: 10.1016/j.comppsych.2016.01.006. Epub 2016 Jan 21.

Tagomori S, Iwase T. Ultrastructural change of enamel exposed to a normal pulsed Nd-YAG laser. Cáries Res, 1995;29:513-520. 
Takamori K, Furukawa H, Morikawa Y, Katayama T, Watanabe S. Basic study on vibrations during tooth preparations caused by high-speed drilling and Er:YAG laser irradiation. S. Lasers Surg Med. 2003;32(1):25-31.

Tanboga I, Eren F, Altinok B, Peker S, Ertugral F. The effect of low level laser therapy on pain during dental tooth-cavity preparation in children. Eur Arch Paediatr Dent. 2011;12(2):93-5.

Thompson V, Craig RG, Curro FA, Green WS, Ship JA. Treatment of deep carious lesions by complete excavation or partial removal: a critical review. J Am Dent Assoc. 2008;139(6):70512.

Townend E, Dimigen G, Fung D. A clínical study of child dental anxiety.Behav Res Ther. 2000;38(1):31-46.

Tyas MJ, Anusavice KJ, Frencken JE, Mount GJ. Minimal intervention dentistry-a review. FDI Commission Project 1-97. Int Dent J. 2000;50(1):1-12.

Williams PT, Jackson DG, Bergman W. An evaluation of the time-dependent dimensional stability of eleven elastomeric impression materials. J Prosthet Dent. 1984 Jul;52(1):120-5.

Valério RA, Borsatto MC, Serra MC, Polizeli SA, Nemezio MA, Galo R, Aires CP, Dos Santos AC, Corona SA. Cáries removal in decíduous teeth using an Er:YAG laser: a randomized splitmouth clínical trial. Clin Oral Investig. 2015 Apr 17.

van Dijken JW, Pallesen U. Clínical performance of a hybrid resin composite with and without an intermediate layer of flowable resin composite: a 7-year evaluation. Dent Mater. 2011 Feb;27(2):150-6.

Van Ockenburg SL, Booij SH, Riese H, Rosmalen JG, Janssens KA. How to assess stress biomarkers for idiographic research? Psychoneuroendocrinology. 2015 Aug 8;62:189-199.

Van Meerbeek B, Peumans $M$, Verschueren $M$, Gladys S, Braem M, Lambrechts $P$, et al. Clínical status of ten dentin adhesive systems.J Dent Res. 1994;73(11):1690-702.

Yfanti K, Kitraki E, Emmanouil D, Pandis N, Papagiannoulis L. Psychometric and biohormonal indices of dental anxiety in children. A prospective cohort study. Stress. 2014 Jul; 17(4):296304.

Ying D, Chuah GK, Hsu CYS. Effect of Er:YAG laser and organic matrix on porosity changes in human enamel. J Dent, 2004;32: 41-46.

Zhang S, Chen T, Ge LH. Evaluation of clínical outcomes for Er:YAG laser application in cáries therapy of children.Beijing Da Xue Xue Bao. 2013; 45(1):87-91.

Zimmer C, Basler HD, Vedder H, Lautenbacher S. Sex differences in cortisol response to noxious stress. Clin J Pain. 2003 Jul-Aug;19(4):233-9. 
Anexos 



\section{ANEXo A - Termo de Consentimento utilizado para os participantes da pesquisa}

\section{TERMO DE CONSENTIMENTO LIVRE E ESCLARECIDO}

Nós, Silvana Aparecida Fernandes Polizeli, Profa. Dra. Silmara Aparecida Milori Corona, Profa . Dra. Maria Cristina Borsatto e Profa. Dra. Aline Evangelista de Souza Gabriel convidamos o estudante: $\longrightarrow$ RG:__ sob responsabilidade de voluntário da pesquisa “REMOÇÃO SELETIVA DE LESÕES DE CÁRIE UTILIZANDO LASER DE ER:YAG EM MOLARES DECÍDUOS: AVALIAÇ̃̃O DA ANSIEDADE DO PACIENTE E ANÁLISE CLÍNICA LONGITUDINAL DAS RESTAURAÇÕES ."

Esta pesquisa vai avaliar se o laser remove a cárie com a mesma capacidade que o "motorzinho", sendo que estudos relatam que os pacientes sentem menos dor quando removemos a cárie com o laser. O laser é uma luz, que não faz ruído ou vibração, e quando bate no dente, remove a cárie. Muitas pessoas deixam de ir ao dentista por sentirem medo do "motorzinho", mas foram feitos estudos que mostraram que as crianças preferem o laser para remover a cárie porque não dói. As crianças serão avisadas antes do tratamento com o laser sobre os possíveis barulhos e estalos (barulho de pipoca) e o possível cheiro que estão associados ao tratamento e elas usarão óculos de proteção especial durante a aplicação do laser para proteger a retina (olho) da luz laser. Serão feitas radiografias durante o tratamento, essas radiografias serão realizadas com a utilização de mínima dose de radiação, por meio de aparelho digital, com avental e protetor de tireóide plumbíferos que protegem a criança e serão fundamentais para o diagnóstico e acompanhamento do tratamento. A radiação provoca efeitos deletérios ao organismo, independentemente da quantidade de exposição. Uma pequena quantidade de radiação não será suficiente para provocar uma manifestação clínica ou genética, mas certamente provocará uma reação celular com quebra e desorganização de molécula. Não se conhecem, com precisão, os efeitos biológicos da radiação para pequenas doses tanto para desenvolver uma lesão. Queremos esclarecer também que a dose de radiação utilizada nessas radiografias são mínimas. As crianças serão anestesiadas e há possibilidade de apresentarem alergia a solução anestésica, como coceiras e urticária. Haverá também durante o tratamento, o isolamento do dente com lençol de borracha (capinha para o dente) que contém látex na sua composição e poderá originar alergia a crianças sensíveis a essa substância.

O dentista fará limpeza de todos os dentes, e todo tratamento restaurador (obturação), além disso, será realizado todo o tratamento que for necessário para que a saúde da boca do voluntário seja atingida. Para termos certeza que o dente está cariado, antes de começarmos vamos tirar raio-x dos dentes. Depois, a cárie vai ser removida de forma seletiva pelo "motorzinho", ou pelo laser. Será colocado embaixo da língua da criança um rolete de algodão para coletar um pouco da saliva que será usada para avaliação do grau de ansiedade que ela vai apresentar durante o tratamento. Quando o dentista estiver tirando a cárie com o laser ou o "motorzinho", usaremos uma cureta (colherzinha), para avaliar se a cárie saiu do dente ou não. Depois disso, faremos a restauração do dente com resina composta (material da mesma cor que o dente). Depois de uma semana, 6 meses e 1 ano, o 
voluntário voltará para a faculdade para mostrar a restauração para os dentistas, onde um exame será feito, para que se possa avaliar o tratamento efetuado. Essa pesquisa apresenta poucos riscos aos participantes, uma vez que o uso do laser já é consagrado pelos pesquisadores, mas se ocorrer algum dano aos participantes, os mesmos serão indenizados. Dessa forma, além de um tratamento sem dor, os participantes terão como vantagem, um acompanhamento odontológico por um período de 1 ano, onde o tratamento será avaliado e se necessário serão efetuados novos procedimentos. 0 voluntário terá como benefício o tratamento dos dentes cariados, e ainda receberá um kit de higiene oral (escova, pasta e fio dental). Um dentista vai ensinar como devemos cuidar dos nossos dentes e mostrar a importância de comer alimentos adequados.

Como responsáveis por esta pesquisa, declaramos que acompanharemos e daremos assistência odontológica a todos os voluntários participantes durante a pesquisa. As despesas referentes ao deslocamento para participação na pesquisa serão custeadas pelos pesquisadores, tanto para a criança quanto para o responsável, uma vez que crianças nesta idade já pagam pelo transporte.

Caso alguém queira desistir de participar da pesquisa, não terá nenhum problema ou prejuízo. Declaramos também que haverá sigilo de dados confidenciais ou de algo que provoque qualquer tipo de constrangimento ao voluntário. Todos os dados serão anônimos.

Qualquer reclamação e ou insatisfação por parte dos voluntários durante a pesquisa poderá ser informada a Secretaria do Comitê de Ética em Pesquisa da FORP-USP pelo contato com a secretária Marcela Scatolin Calache no telefone (16) 3602-0493 no horário das $8 \mathrm{~h}$ às $12 \mathrm{~h}$, de segunda a sexta-feira, desde que os reclamantes se identifiquem, sendo que seu nome será mantido em segredo.

Os pesquisadores poderão ser contactados por meio do número de telefone celular (16) 98825-5518, em qualquer horário caso ocorra alguma intercorrência com os voluntários.

Este Termo de Consentimento Livre e Esclarecido constará de duas vias, rubricadas em todas as suas páginas e assinadas, ao seu término, pelo convidado a participar da pesquisa, ou por seu representante legal, assim como pelo pesquisador responsável, ou pela (s) pessoa (s) por ele delegada (s).

Atenciosamente,

Silvana Aparecida Fernandes Polizeli

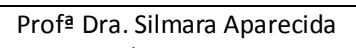
Milori Corona
Profa Dra. Maria Cristina Borsatto
Profa. Dra. Aline Evangelista de Souza Gabriel

Declaro que li, e compreendi os objetivos, riscos e benefícios de minha participação na pesquisa e concordo em participar, por isso assino esse documento. 


\section{ANEXo B - Termo de Assentimento de menor utilizado para os participantes da pesquisa}

\section{Termo de assentimento do menor}

Você está sendo convidado para participar da pesquisa REMOÇÃO SELETIVA DE LESÕES DE CÁRIE UTILIZANDO LASER DE ER:YAG EM MOLARES DECÍDUOS: AVALIAÇÃO DA ANSIEDADE DO PACIENTE E ANÁLISE CLÍNICA LONGITUDINAL DAS RESTAURAÇÕES. Seus pais permitiram que você participe.

Nessa pesquisa, nós queremos saber se as crianças se sentirão mais calmas removendo a cárie (bichinhos dos dentes) se nós usarmos motorzinho ou se nós usarmos uma luz chamada laser.

As crianças que irão participar dessa pesquisa têm de 7 a 9 anos de idade.

Você não precisa participar da pesquisa se não quiser, é um direito seu, não terá nenhum problema se desistir.

A pesquisa será feita aqui nesta sala, que se chama Laboratório de Laser, onde removeremos as cárie dos dentes das crianças. Para isso, será usado o laser ou o motorzinho.

Se você morar longe as faculdade, nós daremos a seus pais dinheiro suficiente para transporte, para também acompanhar a pesquisa.

Ninguém saberá que você está participando da pesquisa, não falaremos a outras pessoas, nem daremos a estranhos as informações que você nos der. Os resultados da pesquisa vão ser publicados, mas sem identificar as crianças que participaram da pesquisa.

Se você tiver alguma dúvida, você pode me perguntar.

$\mathrm{Eu}$ aceito participar da pesquisa REMOÇÃO SELETIVA DE LESÕES DE CÁRIE UTILIZANDO LASER DE ER:YAG EM MOLARES DECÍDUOS: AVALIAÇÃO DA ANSIEDADE DO PACIENTE E ANÁLISE CLÍNICA LONGITUDINAL DAS RESTAURAÇÕES

Entendi que posso dizer "sim" e participar, mas que, a qualquer momento, posso dizer "não" e desistir que ninguém vai ficar furioso.

Os pesquisadores tiraram minhas dúvidas e conversaram com os meus responsáveis.

Recebi uma cópia deste termo de assentimento e li e concordo em participar da pesquisa.

Ribeirão Preto, de de 
ANEXo C- Ficha de ANAMnese

Ficha de Anamnese

Identificação do Paciente:

\begin{tabular}{|l|l|}
\hline Nome: & \\
\hline Data de Nascimento: & \\
\hline Telefone: & \\
\hline Documento: & \\
\hline Endereço: & \\
\hline Filiação: & \\
\hline Data: & \\
\hline
\end{tabular}

Em caso de emergência, contatar:

\begin{tabular}{|l|l|l|l|}
\hline Nome: & & Telefone: & \\
\hline Médico: & & Telefone: & \\
\hline
\end{tabular}


Responda às questões abaixo, marcando a resposta com um X:

\begin{tabular}{|c|c|c|c|c|c|c|c|}
\hline 01 & No momento está em tratamento médico ? & ( ) & Sim & ( ) & Não & ( ) & Não sei \\
\hline 02 & Está tomando alguma medicação no momento? & ( ) & Sim & ( ) & Não & ( ) & Não sei \\
\hline 03 & $\begin{array}{l}\text { Tem ou teve alguma doença como hepatite, } \\
\text { sífilis,... }\end{array}$ & ( ) & Sim & ( ) & Não & ( ) & Não sei \\
\hline 04 & Você é hemofílico? & ( ) & Sim & ( ) & Não & ( ) & Não sei \\
\hline 05 & $\begin{array}{l}\text { Às vezes, sente o coração bater muito } \\
\text { rapidamente? }\end{array}$ & ( ) & Sim & $($ ) & Não & $($ ) & Não sei \\
\hline 06 & Sofre de alguma doença no coração? & $($ ) & Sim & $($ ) & Não & $($ ) & Não sei \\
\hline 07 & Sente falta de ar com frequência? & ( ) & Sim & ( ) & Não & ( ) & Não sei \\
\hline 08 & Tem tosse persistente com freqüência? & ( ) & Sim & $($ ) & Não & ( ) & Não sei \\
\hline 09 & Costuma ter os pé ou pernas inchados? & $($ ) & Sim & $($ ) & Não & ( ) & Não sei \\
\hline 10 & Alguma vez escarrou sangue? & ( ) & Sim & ( ) & Não & ( ) & Não sei \\
\hline 11 & Você é diabético? & ( ) & Sim & ( ) & Não & ( ) & Não sei \\
\hline 12 & Costuma sentir muita sede? & ( ) & Sim & ( ) & Não & ( ) & Não sei \\
\hline 13 & $\begin{array}{l}\text { Quando se fere, as feridas demoram a } \\
\text { cicatrizar? }\end{array}$ & ( ) & Sim & ( ) & Não & ( ) & Não sei \\
\hline 14 & Sangra muito quando se fere? & ( ) & Sim & ( ) & Não & ( ) & Não sei \\
\hline 15 & Tem algum tipo de alergia? & ( ) & Sim & ( ) & Não & ( ) & Não sei \\
\hline 16 & Já precisou de transfusão de sangue? & ( ) & Sim & ( ) & Não & ( ) & Não sei \\
\hline 17 & Alguma vez tomou Penicilina? & ( ) & Sim & ( ) & Não & ( ) & Não sei \\
\hline
\end{tabular}

DECLARO que o respondido acima é verdadeiro.

de de20 
ODONTOGRAMAS:

Inicial ( ) Final ( )

DENTIÇÃO PERMANENTE

\begin{tabular}{|c|c|c|c|}
\hline Dentes & Estado atual em & Dentes & Estado atual em \\
\hline 18 & & 38 & \\
\hline 17 & & 37 & \\
\hline 16 & & 36 & \\
\hline 15 & & 35 & \\
\hline 14 & & 34 & \\
\hline 13 & & 33 & \\
\hline 12 & & 32 & \\
\hline 11 & & 31 & \\
\hline 21 & & 41 & \\
\hline 22 & & 42 & \\
\hline 23 & & 43 & \\
\hline 24 & & 44 & \\
\hline 25 & & 45 & \\
\hline 26 & & 46 & \\
\hline 27 & & 47 & \\
\hline 28 & & 48 & \\
\hline
\end{tabular}


Inicial ( ) Final ( )

DENTIÇÃO DECÍDUA

\begin{tabular}{|c|c|c|c|}
\hline Dentes & Estado atual em & Dentes & Estado atual em ___ \\
\hline 55 & & 75 & \\
\hline 54 & & 74 & \\
\hline 53 & & 73 & \\
\hline 52 & & 72 & \\
\hline 51 & & 71 & \\
\hline 61 & & 81 & \\
\hline 62 & & 82 & \\
\hline 63 & & 83 & \\
\hline 64 & & 84 & \\
\hline 65 & & 85 & \\
\hline
\end{tabular}

